\title{
Infrared radiative performance of urban trees: spatial distribution and interspecific comparison among ten species in the UK by in-situ spectroscopy
}

Article

Accepted Version

Creative Commons: Attribution-Noncommercial-No Derivative Works 4.0

Deng, J., Pickles, B. J., Smith, S. T. and Shao, L. (2020) Infrared radiative performance of urban trees: spatial distribution and interspecific comparison among ten species in the UK by in-situ spectroscopy. Building and Environment, 172. 106682. ISSN 0360-1323 doi:

https://doi.org/10.1016/j.buildenv.2020.106682 Available at https://centaur.reading.ac.uk/88560/

It is advisable to refer to the publisher's version if you intend to cite from the work. See Guidance on citing.

To link to this article DOI: http://dx.doi.org/10.1016/j.buildenv.2020.106682

Publisher: Elsevier

All outputs in CentAUR are protected by Intellectual Property Rights law, including copyright law. Copyright and IPR is retained by the creators or other copyright holders. Terms and conditions for use of this material are defined in the End User Agreement. 


\section{www.reading.ac.uk/centaur}

\section{CentAUR}

Central Archive at the University of Reading

Reading's research outputs online 
3 Infrared radiative performance of urban trees: spatial distribution

4 and interspecific comparison among ten species in the UK by in-situ

5 spectroscopy

6

7 Jie Deng ${ }^{\text {a,* }}$, Brian J. Pickles ${ }^{\text {b }}$, Stefan T. Smith ${ }^{\text {a, }}$ Li Shao ${ }^{\text {a }}$

8

$9{ }^{\text {a }}$ School of The Built Environment, University of Reading, Whiteknights, Reading, 10 Berkshire, RG6 6DF, UK

$11 \mathrm{~b}$ School of Biological Sciences, University of Reading, Harborne Building, 12 Whiteknights, Reading RG6 6AS, UK.

$14 *$ Corresponding author:

15 E-mail address: j.deng@ reading.ac.uk; deng-jie2@163.com (J. Deng) 
 \\ Infrared radiative performance of urban trees: spatial distribution
} and interspecific comparison among ten species in the UK by in-situ spectroscopy

\begin{abstract}
Understanding the ways in which tree species interact with solar radiation has previously focused on transmission and reflection of sunlight, typically by examining individual leaves. Here we used a tree crown spectroscopy measurement method to conduct in-situ tests on the radiative performance of ten commonly planted tree species in the UK. Tree crown transflectance (comprehensive effect of transmission and reflection) was examined to determine i), how radiative performance of individual trees varies spatially within a species, and ii), how infrared radiative performance differs between tree species. Our results show that tree crown transflectance depends on the combination of tree crown morphology, local foliage distribution (leaf density, gaps in crown foliage contour, concave or convex crown shapes), solar altitude and leaf size. Spatially, the strongest tree crown transflection was found primarily towards sky on the sunlit side of trees rather than towards the zenith, meaning that infrared transflection towards surrounding buildings and pedestrians is substantial. For all ten species, the tree crown transflectance in the frontal sunlit area was linearly correlated with solar altitude on sunny days. Hence, a solar altitude of $45^{\circ}$ was chosen as the benchmark condition for comparing interspecific differences. Interspecific comparison indicated
\end{abstract}



dependent on leaf size when no obvious gaps or concave shapes were present within

40 the tree crowns. Our findings provide insights for understanding radiative interactions

41 between urban trees and surrounding built environment, as well as for tree species

42 selection in urban heat stress mitigation.

43

44 Keywords: Urban trees; Infrared radiative performance; Tree crown spectroscopy; Tree

45 species; Urban microclimate 
List of symbols

\begin{tabular}{|c|c|}
\hline Nomenclature & \\
\hline$A_{\text {foliage }}$ & net foliage area of a measuring patch with foliage gaps, $\mathrm{m}^{2}$ \\
\hline$A_{\text {patch }}$ & $\begin{array}{l}\text { total area of a measuring patch in viewing vision of the fiber-optic } \\
\text { tip, } \mathrm{m}^{2}\end{array}$ \\
\hline$A_{\text {void }}$ & void area of a measuring patch with foliage gaps, $\mathrm{m}^{2}$ \\
\hline$D_{\text {measured }}$ & $\begin{array}{l}\text { sampling distance from the fiber-optic tip to a measuring patch on } \\
\text { tree crown contours }\end{array}$ \\
\hline$V A$ & $\begin{array}{l}\text { viewing angle of the spectrometer fiber-optic tip relative to } \\
\text { horizontal plane, }\end{array}$ \\
\hline$V R$ & void ratio of a measuring patch with foliage gaps, - \\
\hline$\overline{x_{l}}$ & the $\underline{i}$-th average component value of the statistical mean spectrum, - \\
\hline Greek symbols & \\
\hline$\alpha$ & solar altitude, ${ }^{\circ}$ \\
\hline$\lambda$ & wavelength, $\mathrm{nm}$ \\
\hline$\tau R$ & $\begin{array}{l}\text { transflectance (comprehensive effect of transmission and reflection) } \\
\text { of tree crown contour or canopy patch, - }\end{array}$ \\
\hline$\tau R_{\text {mean }, 800-900}$ & $\begin{array}{l}\text { mean transflectance in the near infrared wavelength range of } 800- \\
900 \mathrm{~nm},-\end{array}$ \\
\hline$\tau R(\lambda)$ & spectral transflectance at wavelength $\lambda \mathrm{nm},-$ \\
\hline$\tau R_{\text {foliage }}$ & $\begin{array}{l}\text { net transflectance of foliage excluding foliage gaps in a measuring } \\
\text { patch,- }\end{array}$ \\
\hline$\tau R_{\text {meas_bgd }}$ & background noise signal in sampling transflectance spectrum, - \\
\hline$\sigma_{A, x}$ & $\begin{array}{l}\text { type A standard error (uncertainty) of a variable } x \text {, unit is the same } \\
\text { as } x\end{array}$ \\
\hline Abbreviations & \\
\hline$I R$ & infrared \\
\hline$L A I$ & leaf area index \\
\hline$P C A$ & principal component analysis \\
\hline$S A z$ & solar azimuth (direction) \\
\hline$S V F$ & sky view factor \\
\hline$U H I$ & urban heat island \\
\hline$V I S$ & visible \\
\hline
\end{tabular}




\section{Introduction}

Heat waves frequently hit many cities throughout the world and record temperatures are being experienced in many regions in recent years due to the increasing temperatures associated with greenhouse gas emissions [1][2]. It is documented that heat waves have remarkably negative influences on the health of urban inhabitants and contribute significantly to mortality of residents [1][3][4]. Furthermore, anthropogenic global warming is increasing the frequency, duration and intensity of heat waves [5], with the urban heat island (UHI) effect intensifying heat stress under extreme hot climates [6]. In the pursuit of creating benign urban environments to improve human health and well-being, it is imperative to seek effective solutions or strategies for mitigating heat waves and adapting to climate change.

Trees and green spaces enable the provision of better ecosystem services to urban environments [7]. For example, urban trees help to mitigate heat waves through radiative shading [8] and evapotranspiration [9], resulting in lowered air temperatures that help to regulate outdoor thermal comfort [10][11][12]. Gillner et al. [13] demonstrated that street trees played a key role in mitigating effects of heat and drought at highly sealed urban sites. Numerical simulations have shown that urban green coverage (trees and grasslands) helped to mitigate human heat stress under different climates [14][15], and the same point was argued in a systematic review of urban greening [16]. Spatial configuration of trees (individual trees versus different types of spacing and/or aggregations) may show significant, but inconsistent results (including 
both positive and negative effects) of urban heat mitigation in cities with different climatic conditions [17][18]. Zhou et al. [17] presented that percent cover of trees was more important than their spatial configuration in predicting land surface temperature in Baltimore, while the opposite was found in Sacramento. Reasonable urban tree design approaches have a good performance in mitigating daytime and nighttime UHI effects in urban environments [19][20], and an appropriate combination of vegetation and urban geometry can help to mitigate the adverse effects of UHI and provide a better pedestrian thermal comfort [21][22]. More than that, the cooling effects of urban trees or green roofs through radiative shading and evapotranspiration also contribute to building energy savings [12][23] [24] [25]. It is clear that urban forests and trees make important contributions to cities by providing a multitude of benefits [7]. However, tree species have different physiological responses to heat waves and extreme heat events [26][27][28], depending on heat stress adaptability and water availability for the tree species [29], meaning that some trees cope better with high urban temperatures than others [26][30].

To understand urban tree cooling effects and physiological responses, researchers have been focusing on metrics of assessing outdoor thermal comfort (e.g. surface temperature, mean radiant temperature, physiological equivalent temperature), tree physiological indices (e.g. leaf or crown temperature, leaf area index, stomatal conductance, evapotranspiration rate), determinants and quantification of tree cooling capacity, tree shade effects and so on. Surface temperatures of trees and green spaces 
are typically $10-20{ }^{\circ} \mathrm{C}$ lower than those of sealed ground or built surfaces exposed to sunlight in summer, leading to a significant reduction of mean radiant temperature [13][30][31]. Leuzinger et al. [30] reported tree crown temperatures of ten common tree species planted in Central European cities and declared that tree surface temperatures were circa -1 to $+4{ }^{\circ} \mathrm{C}$ higher than the ambient temperature. They found trees in parks were significantly cooler than those surrounded by sealed ground and small-leaved trees remained cooler than large-leaved trees. Furthermore, surface temperatures of different tree species varied considerably, and the SVF (sky view factor - the ratio of the amount of the sky that can be seen from a given point on a surface to that potentially available, ranging from 0 to 1 ) value had a significant effect on tree surface temperatures [18][32]. It is presumed that the mean radiant temperature, which is linked to global temperature, air temperature and wind speed [19], is closely related to the urban thermal comfort [22]. Park et al. [33] proposed a multilayer mean radiant temperature model for pedestrians in a street canyon with trees. Physiological equivalent temperature is also an important assessing index of outdoor thermal comfort [18][34]. Zölch et al. [35] showed that planting trees had the strongest impact with an average physiological equivalent temperature reduction of $13 \%$ compared with existing vegetation. Zheng et al. [31] measured the influence of trees on the outdoor thermal environment in subtropical areas through field tests of relevant physiological indices and microclimatic parameters. They found that the widely planted fig tree Ficus microcarpa had the best cooling performance among four tree species studied, with the maximum reduction of physiological equivalent temperature due to the highest leaf area 
index (LAI).

As to the determinants of tree cooling effects in terms of tree physiological indices, Morakinyo et al. [36] revealed that LAI was the main driver of tree cooling for outdoor temperature regulation, followed by trunk height, tree height and crown diameter. LAI was also highlighted by Armson et al. [37] and Rahman et al. [38]. Zhang et al. [39] stated that tall trees with a large LAI and canopy diameter should be a priority to improve the comfort of outdoor environments. Furthermore, different tree species may differ in microclimate benefits. Sanusi et al. [40] declared that the microclimatic benefits in streets with Ulmus procera and Platanus x acerifolia trees were significantly greater than the street with Eucalyptus scoparia trees, in terms of air temperature, relative humidity, solar radiation, mean radiant temperature, wind speed. In assessing a tree's cooling capacity via transpiration, it is presumed that different tree species have significant difference in evaporative cooling [24][41][42][43]. For example, as reported in [44], Tilia cordata trees with higher LAI and sap-wood area provided three times more transpiration than Robinia pseudoacacia. Konarska et al. [45] observed that nighttime transpiration in all the seven species they studied amounted to 7 and $20 \%$ of midday transpiration of sunlit and shaded leaves, respectively, in a high latitude city in Gothenburg, Sweden. There are some other ways of quantifying the cooling effects of urban trees through transpiration. For instance, Wang et al. [46] quantified the cooling capacity of urban trees as the surface cooling rate (the negative ratio of land surface temperature changes to fractional tree cover changes). They found that the surface 
cooling rate was dominated by plant transpiration, up to $1.336{ }^{\circ} \mathrm{C}$ per percentage of fractional tree cover in heat waves in cities of the contiguous United States. Additionally, tree shade provides a good outdoor thermal comfort for pedestrians and enables energy savings. Rahman et al. [44][47] investigated vertical air temperature gradients under tree shades during summer days. Tree radiative shading effect was simulated by Upreti et al. [8] in a regional built environment, who predicted the capacity of urban trees in reducing urban surface and air temperature by about $2-9{ }^{\circ} \mathrm{C}$ and $1-5{ }^{\circ} \mathrm{C}$, respectively. It is argued that shade trees have more prominent energy saving potential than urban lawns in a desert city [12]. Urban lawns tend to be hugely wasteful of water resources, so well chosen species of shade trees or xerophytes may be far more energy efficient than lawns in arid or semi-arid environments [48][49].

Apart from research into urban tree cooling effect, reasonable tree planting strategies were widely considered. Reasonable arrangement of spacing and size of street trees was proven to be beneficial for decreasing pedestrian mean radiant temperature [50]. Different tree planting strategies are available in [39][51][52][53][54][55][56] for improving outdoor thermal comfort in different scenarios and climates.

Generally, previous research into the cooling effect of trees in regulating urban microclimates simplified the physical characterization of radiative performance of trees [8][39][57][58][59]. Some studies have excluded the radiative shading effect of trees in urban microclimatic modelling [60][61]. Where foliage albedo values for different tree 
species have been incorporated in microclimate modelling to illustrate their influences on thermal environment they are commonly fixed [59], yet the foliage albedo of trees varies temporally and spatially throughout a day (as presented in sections 4.2.3 and 4.3 of the present study). To better understand the cooling effect and capacity of urban trees, it is essential to characterise the radiative performance of different tree species from the perspective of physical characteristics, especially in the near infrared (NIR) region. In an earlier study, we established a novel methodology of characterising infrared (IR) radiative performance of urban trees using tree crown spectroscopy [62]. Experimental tests on Tilia cordata (aka small-leaved lime or little-leaf linden), a commonly planted tree species in the UK and Europe, were carried out to demonstrate the impact factors of IR radiative performance qualitatively in terms of transflectance at the tree crown level. However, the way in which IR radiative performance varies spatially across a tree crown and interspecific differences remain unanswered. Hence, the present study aims to explore spatial distribution of IR radiative performance across a tree crown, as well as to ascertain differences of IR radiative performance levels in tree species that are often planted in the UK. Since the radiative performance of tree species in terms of the tree crown transflectance varies with solar time throughout a day in a clear sky, as stated in our previous work [62], the way in which transflectance varies with solar time was explored as well, helping to make a benchmark for comparing interspecific performance differences. Ten commonly planted tree species in the UK were chosen for extensive in-situ tests of tree crown transflectance on sunny days using the established spectroscopy measurement method, in order to assess interspecific 

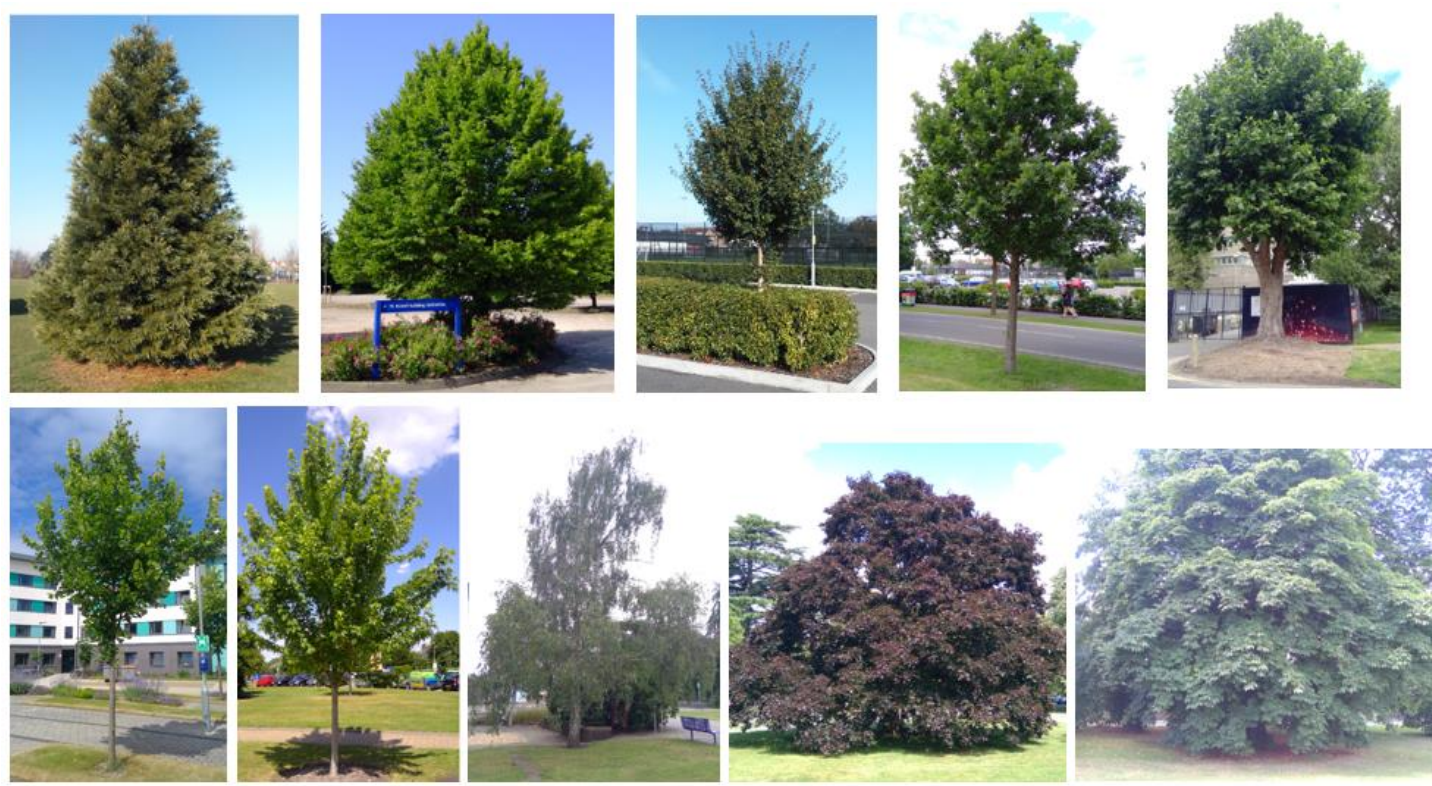

Figure 1. Ten tree species selected in field tests, top row left to right: Sequoiadendron 
197

198

199

200

201

202

203

204

205

206

207

208

209

210

giganteum (giant sequoia), Carpinus betulus ('Fastigiata' cultivar, hornbeam), Acer campestre (field maple), Quercus robur (English oak) and Platanus x acerifolia (London plane); bottom row left to right: Tilia platyphyllos (large-leaved lime), Acer $\mathrm{x}$ freemanii (autumn blaze maple), Betula pendula (silver birch), Acer platanoides ('Schwedleri' cultivar, copper Norway maple) and Aesculus hippocastanum (horse chestnut).

\subsection{Test methods, instruments and facilities}

We previously established a methodology for characterising IR radiative performance of urban trees using tree crown spectroscopy [62]. The term tree crown transflectance $(\tau R)$ or transflection, which represents comprehensive radiative performance of trees at the crown level, is introduced in contrast to reflectance or transmittance at tree leaf levels. This is because when an optical sensor (i.e. spectrometer fiber-optic cable) is positioned at one side of trees to measure the radiative performance of 'a patch of tree crown surfaces' (abbreviated as 'measuring patch' hereafter), light received by the spectrometer usually comprises single-reflected, multi-reflected, multi-transmitted and transmitted-reflected rays through leaves.

A Black-Comet-SR model CXR-SR (StellarNET Inc., Tampa, Florida, USA) concave grating miniature spectrometer with a wavelength range of $350-1000 \mathrm{~nm}$ and a spectroradiometer mode was used for in-situ tests of tree crown transflectance. It covers the full visible (VIS) region $(350-700 \mathrm{~nm})$ and an important spectrum transition from 
VIS to NIR around $700 \mathrm{~nm}$ where the leaf reflectance and crown transflectance jump sharply (see testing results in section 4). Its spectral resolution is $0.5 \mathrm{~nm}$. In the spectroradiometer mode, the fiber-optic tip can be fitted with a cosine receptor which allows measurement of solar spectra irradiance in a $180^{\circ}$ field of view in the $350-1000$ $\mathrm{nm}$ wavelength range. The spectroradiometer mode was only used for solar spectral irradiance measurements in conditions of different viewing angles of the fiber-optic tip.

Regarding the test facilities, a scalable tripod with a full height of $8 \mathrm{~m}$ was used to hold and position the fiber-optic cable of the miniature spectrometer in the field tests, as shown in Figure 2(a). The fiber-optic cable was mounted onto the top of the tripod at one end and connected to a data acquisition laptop at the other. A USB camera was fixed close to the fiber-optic tip in order to capture viewing vision of the latter in field tests. The miniature spectrometer was powered through a USB cable connected to the laptop. The battery when fully charged usually lasted for about five hours powering both the laptop and the spectrometer. The viewing angle of the optical sensor can be adjusted in all directions. The fiber-optic cable was usually used without any cosine receptor and had a field of view of $25^{\circ}$. A reflectance standard RS50 shown in Figure 2(b) was adopted to measure reference spectra. The reference spectrum was always sampled in a vertical plane in the transient solar azimuth (SAz) direction, as justified in our previous work [62]. Particularly, for a test sequence of transflectance spatial distribution, a single vertical reference plane was employed, and the test sets were performed within several minutes. Appropriate measuring distance from the trees should be chosen to make the measuring results robust. It was found that the sampling 
243 on the tree crown surfaces could not be too close (e.g. less than $1.5 \mathrm{~m}$ ), as it would lead 244 to higher transflectance levels than a sampling distance beyond $2.0 \mathrm{~m}$ where the 245 measuring result was robust. This measurement issue was greatest for tree species with 246 large-sized leaves such as Platanus $x$ acerifolia (London plane), Aesculus 247 hippocastanum (horse chestnut), in which the IR transflectance would be overestimated 248 by $25 \%$ at a closer sampling distance (e.g. $1.0 \mathrm{~m}$ ) due to a specular reflectance effect 249 from partial leaf surfaces. In view of this, the sampling distance was kept between 2.0$2505.0 \mathrm{~m}$ for most of the tested trees, depending on the tree crown diameters and the 251 viewing vision of the USB camera. In some small trees, e.g. Acer campestre (field 252 maple) a distance of 1.5-2.0 $\mathrm{m}$ was chosen because the height of the trees was less than $2535 \mathrm{~m}$ and the diameter of the tree crowns was less than $3 \mathrm{~m}$.

254

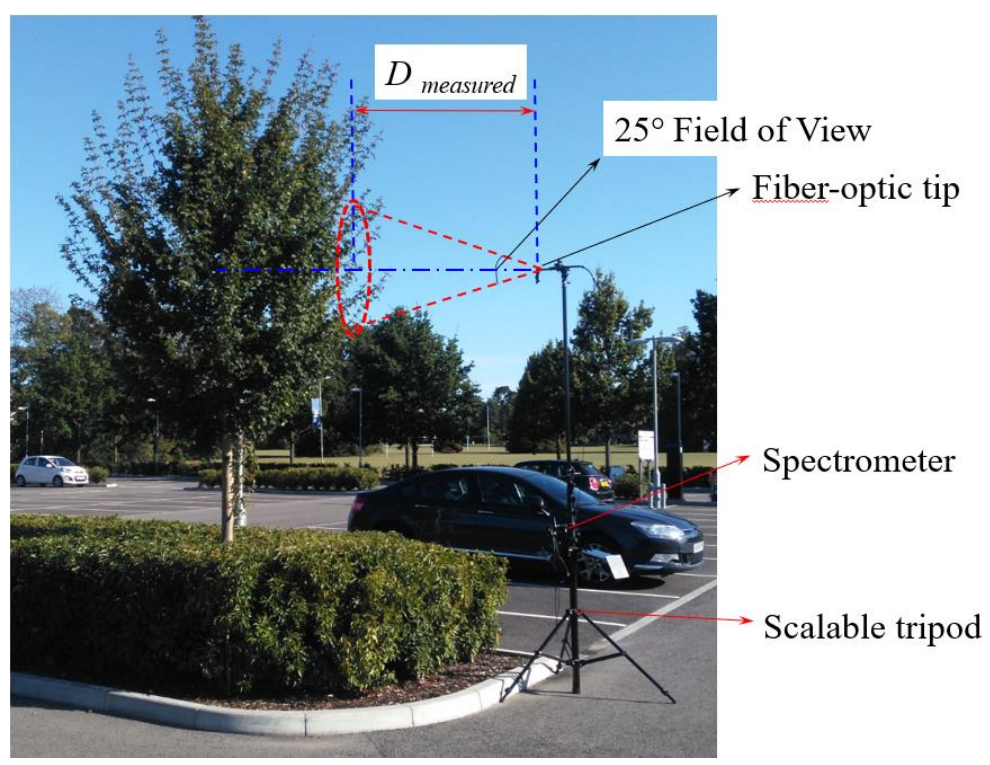

(a) 


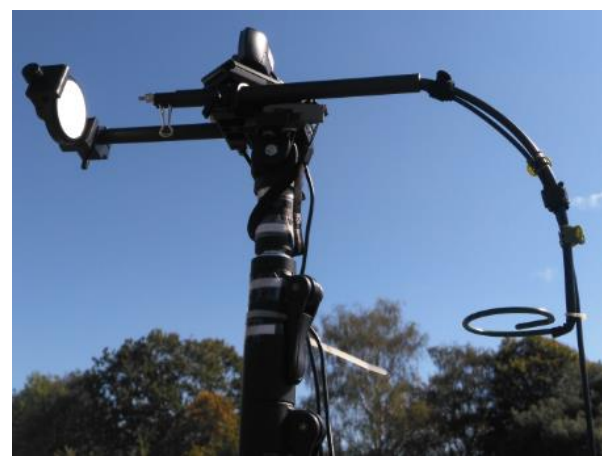

257 Figure 2. (a) A scalable tripod holding the optical fiber spectrometer for field tests; (b)

Optic fiber tip of the spectrometer and a reflectance standard RS50.

A model SM2500 spectrometer (Spectral Evolution, Haverhill, Massachusetts, USA) (wavelength range: $350-2500 \mathrm{~nm}$ and wavelength reproducibility of $0.1 \mathrm{~nm}$ at an accuracy of 0.5 bandwidth) was used in the laboratory to measure leaf reflectance of different tree species, in contrast to the tree crown transflectance levels. The spectrometer was deployed together with a leaf clamp supplied by the manufacturer for leaf reflectance measurements. This spectrometer with a broad spectral range was bulky and expensive, thus not suitable for mounting on a tripod for field tests.

\subsection{Test conditions}

To explore spatial distribution rules of the radiative performance of individual trees, one fastigiate hornbeam tree of $7.0 \mathrm{~m}$ height and one Acer campestre tree of $4.4 \mathrm{~m}$ height were primarily measured at multiple times, with different viewing angles of the

273 spectrometer fiber-optic tip pointing at different spatial locations of their crowns. Wider

274 field tests of the ten tree species were implemented to explore interspecific differences 
275

277 intraspecific (within-species) and interspecific (between-species) variability in

278 transflectance. All field tests of tree crown transflectance were carried out on sunny

279 days or in sunny time slots without clouds shading the sun, in order to maintain a

of the radiative performance in terms of the transflectance in the sunlit area of trees. At least five individual trees were sampled for each species in order to assess both constant solar irradiance for the reference spectrum and the sampling transflectance spectrum. Measuring heights of the transflectance were usually chosen around the center height of the tree crown within $\pm 1.0 \mathrm{~m}$ deviation. Background noise signal was measured for several individual trees to assess its impact on measurements, which was found to be negligible as shown in section 4.2.1.

In addition to meteorological microclimate conditions (outdoor air temperature, incoming and outgoing shortwave radiation, incoming and outgoing longwave radiation), the soil moisture contents and physiological conditions (leaf temperature) of a single fastigiate hornbeam (Carpinus betulus) tree were monitored during the testing period of June to September 2019, providing information reference for the test conditions. Chlorophyll fluorescence and heat stress of five tree species were measured to inform their physiological stress status. Reflectance spectra of multiple individual leaves of various tree species were also measured in the lab for contrast.

\section{Data processing and error analysis}

Repeated measurements of leaf reflectance or tree crown transflectance spectra for 
various tree species were implemented to obtain the statistical mean. Notate $M$ as the number of spectra samples of a specific tree species. For each spectrum sample, assume that $N$ rows of spectral values are recorded at different wavelength intervals. The statistical mean spectrum is calculated based on the sample component values in each row, as given in Equation (1).

$$
\overline{x_{l}}=\sum_{j=1}^{M} x_{i, j}
$$

where $\overline{x_{l}}$ is the $\underline{i}$-th average component value of the statistical mean spectrum, while $x_{i, j}(i=1,2,3, \ldots, N ; j=1,2,3, \ldots, M)$ denotes the $\underline{i}$-th measured component value in the $j$-th sample spectrum.

With respect to error analysis of the statistical mean spectrum of the tree crown transflectance or the reflectance of individual leaves, A-type standard error (uncertainty) is usually used to estimate the statistical mean errors [64], as described in Equation (2).

where $\sigma_{A, x}$ is the A type standard error of a variable $x, M$ is the number of samples, $\bar{x}$ is the statistical mean value of variable $x$, and $x_{j}$ represents the $j$-th sample value.

The standard error of the statistical mean tree crown transflectance or leaf reflectance spectrum at each wavelength band is therefore given by:

$$
\sigma_{A, \tau R}(i)=\sqrt{\frac{1}{M(M-1)} \sum_{j=1}^{M}\left(x_{i, j}-\bar{x}_{l}\right)^{2}}
$$


321 where $\sigma_{A, \tau R}(i)$ is the $i$-th component of the A-type standard error for the transflectance

$322(\tau R)$ spectrum.

324 When calculating the statistical mean, if a spectrum in the samples was found to be

325 outside of the $99.8 \%$ confidence interval, i.e. $\left[-3 \sigma_{A, T R},+3 \sigma_{A, T R}\right]$, it was identified as 326 a spectrum outlier. The statistical mean of the targeted spectrum was then recalculated 327 excluding any outliers to minimize the contribution of measurement errors or non-target 328 biological processes such as damaged or discolored leaves.

\subsection{Statistical analyses using PCA (principal component analysis)}

Unless otherwise noted all statistical analyses using PCA were carried out in R version to analyse spectral data. Due to the nature of this data, ordination using Principal Component Analysis (PCA) and Principal Coordinates Analysis (PCoA or MDS Multidimensional Scaling) generate the same outcome; for consistency these ordinations are referred to as PCA. Briefly, PCA takes a multivariate dataset of potentially correlated variables and transforms them into fewer, uncorrelated variables

338 (principal components). This approach is commonly applied in ecology (see Legendre and Legendre [69]) and has previously been applied to leaf spectral data in remote sensing studies (e.g. Cavender-Bares et al. [70]). Spectral data (transflectance measured across the range 350-1000 $\mathrm{nm}$ ) were interpolated for each of 67 individual trees from 
342

343

344

345

346

347

348

349

350

351

352

353

354

355

356

357

358

359

360

$0.5 \mathrm{~nm}$ bands into $5 \mathrm{~nm}$ bands and then scaled prior to analysis. The 10 -fold reduction in data points following interpolation (1300 to 130 bands per tree) led to a loss of only

$0.1 \%$ of overall explained variance. Significant correlations between PCA axes and spectra were used to assess the specific differences represented by the axes, and species was used as a grouping variable.

Further examination of inter- and intra-specific differences in transflectance profiles for 350-1000 nm was conducted by converting PCA eigenvalues into pairwise euclidean distances and then applying permutational multivariate analysis of variance (PERMANOVA) on the resulting distance matrices. The multivariate homogeneity of dispersion (variance) was then assessed to examine the extent to which observed differences i) could be attributed to interspecific differences in transflectance values, or ii) may have been confounded by differences in intraspecific variance.

\section{Results and discussion}

Figure 3 illustrate the flow chart of research framework in the discussion, in order to determine i), how radiative performance of individual trees varies spatially within a species, and ii), how infrared radiative performance differs between tree species. 


\section{Leaf reflectance of multiple tree species measured in the laboratory}

(section 4.1)

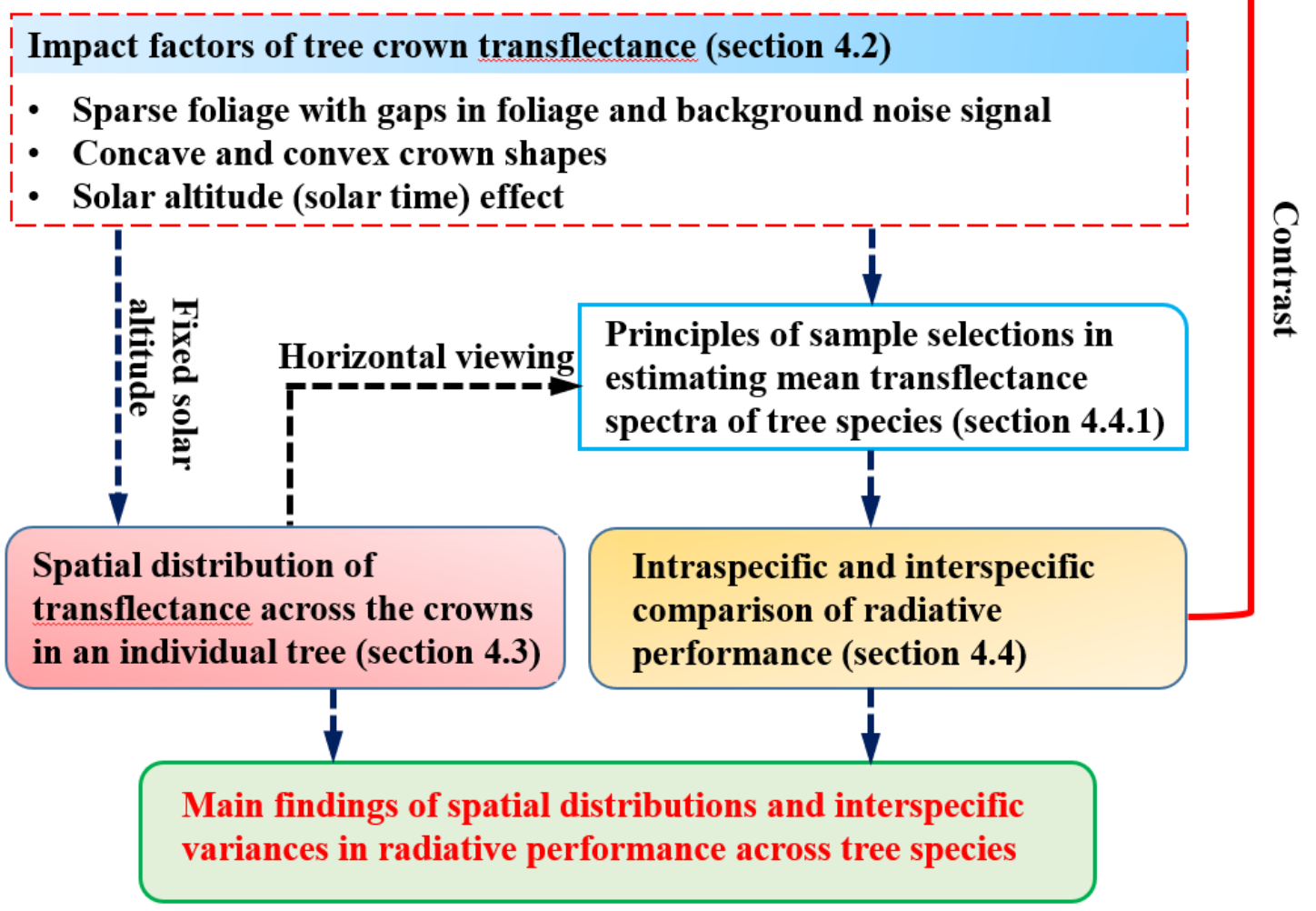

Figure 3. Flow chart of the research framework in discussion.

\subsection{Leaf reflectance measured in the laboratory}

Leaf reflectance spectra of 9 targeted tree species (except Sequoiadendron giganteum) were measured at multiple times in the laboratory using the SM2500 spectrometer (Spectral Evolution) with a leaf clamp, in order to estimate statistical mean leaf reflectance spectra. Leaf reflectance of the species Sequoiadendron giganteum was not measured, as the spectrometer could not be used to measure individual needle leaves. For each tree species, 10 leaves were collected randomly from individual trees and 510 trees were sampled. Reflectance spectra of the collected leaves were measured within 1 hour after leaf collections to guarantee that the leaves would not lose moisture. 
373 Each selected leaf was measured once, and the measuring point was chosen randomly 374 with consideration of avoiding main leaf veins. Figure 4 gives the statistical mean leaf 375 reflectance spectra of 9 tree species, indicating there is a minor difference of mean leaf 376 reflectance spectra among various tree species (within $\pm 4 \%$ of spectral reflectance 377 values). The standard mean errors of spectral reflectance of various tree species in the 378 wavelength range of $400-2500 \mathrm{~nm}$ were within $\pm 0.5 \%$ with a large number of samples 379 (50-100 samples for each species). Data on statistical mean reflectance spectra of 380 leaves across species can be accessed in Appendix $\boldsymbol{A}$.

381

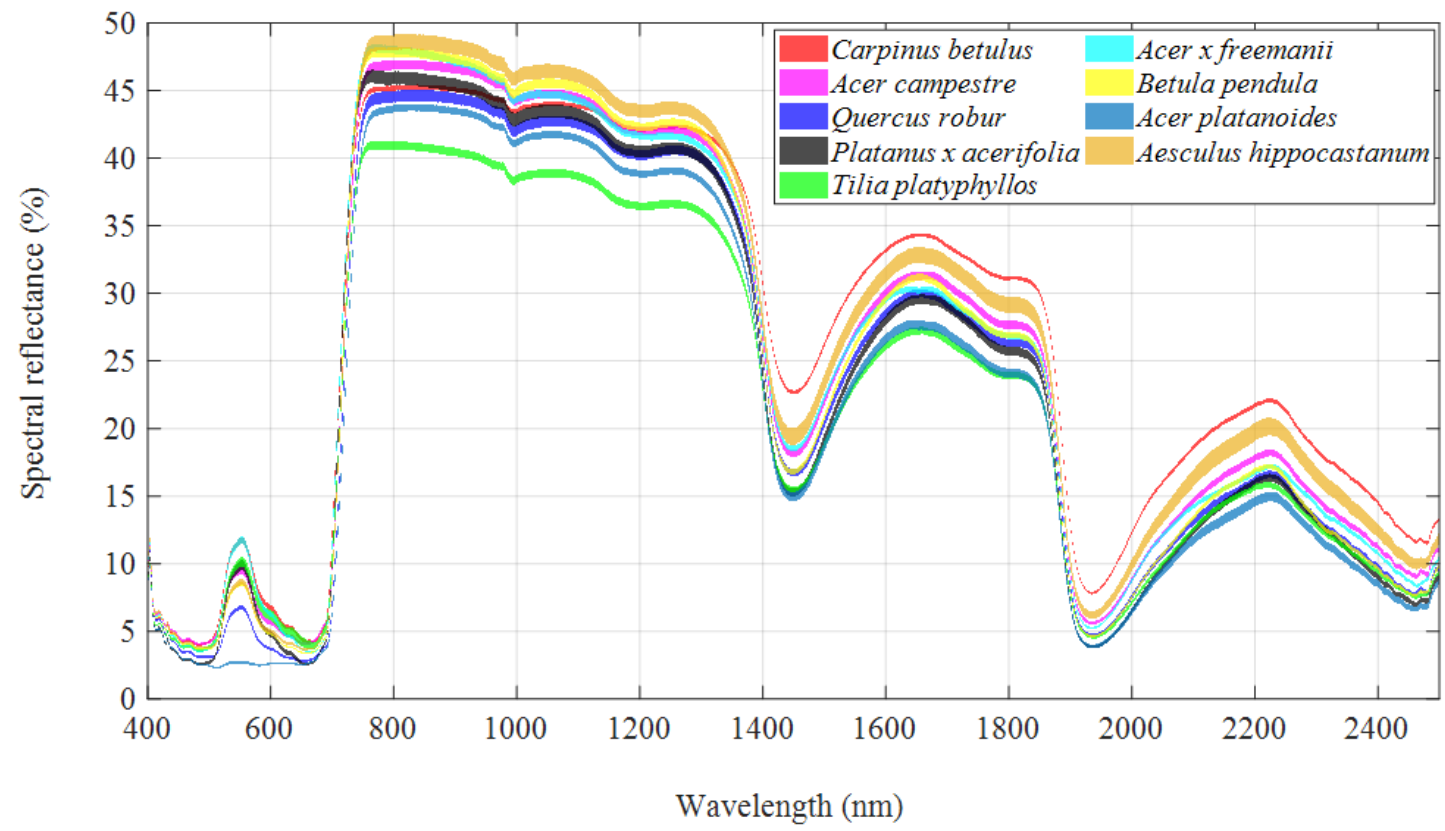

Figure 4. Standard mean error bands of leaf reflectance spectra of nine tree species measured in the laboratory and sampled from 5-10 trees for each species.

\subsection{Impact factors of tree crown transflectance}

Through a multitude of in-situ tests, it was found that visibly non-uniform foliage 
388

389

distribution in the measuring patches of tree crown contours, such as sparse foliage with gaps in crown foliage and/or concave crown shapes, would affect tree crown transflectance $(\tau R)$ to different extents. On the other aspect, our previous work indicated that solar time was one of the most important factors impacting $\tau R$ levels [62]. It is therefore necessary to elucidate the impacts and determine the principles of sample selections for estimating the radiative performance levels of multiple tree species.

\subsubsection{Impact of sparse foliage with gaps in crown foliage and background noise signal}

Sparse foliage is commonly visible at some locations of tree crowns. To estimate measurement errors of the measuring patches with gaps in the sparse foliage and examine the impact of background noise signal penetrating the gaps, it is essential to measure the transflectance of the measuring patch along with the background noise signal. Void ratio of the gaps in the measuring patch should be also determined, in order to correct the net transflectance of the sparse foliage by excluding background noise signal. Total area of a measuring patch with gaps $\left(A_{\text {patch }}\right)$ is sum of the net foliage area $\left(A_{\text {foliage }}\right)$ and the void area $\left(A_{\text {void }}\right)$ in equation (5). Void ratio of the gaps $(V R)$ is calculated in equation (6). Relation between the measured transflectance $\left(\tau R_{\text {meas_patch }}\right)$, the net transflectance of foliage $\left(\tau R_{\text {foliage }}\right)$ and the background noise signal ( $\left.\tau R_{\text {meas_bgd }}\right)$ is described by equation (7) based on radiative energy conservation. Thus, the net transflectance of foliage ( $\left.\tau R_{\text {foliage }}\right)$ is rearranged in equation (8) and the relative error is estimated by equation (9). 


$$
A_{\text {patch }}=A_{\text {foliage }}+A_{\text {void }}
$$

\section{Take the $\tau R$ measurement of a Tilia platyphyllos tree with sparse foliage as an example} to illustrate the impact of background noise. Figure 5(a) shows the viewing vision of the tree crown $\tau R$ measurement in the sunlit area and SAz (solar azimuth) direction with solar altitude $\alpha=34^{\circ}$. The void ratio of gaps (VR) in the vision was estimated by the Image J software [71], resulting in VR $=23.3 \%$ (see Figure 5(b)). The net $\tau R$ of the foliage ( $\tau R_{\text {foliage }}$ ) was calculated in equation (8). Figure 5(c) shows the corrected net foliage $\tau R$ spectrum excluding gaps in foliage compared to the measured $\tau R$ spectra. It suggested that the measurement error by the background noise was very small (within 3\% deviation). Furthermore, the net $\tau R$ of the foliage was lower (-4\% deviation of IR $\tau R$ in this case) than the $\tau R$ of a dense measuring patch in another Tilia platyphyllos tree, indicating that a sparse foliage (sparse leaf density) degraded the $\tau R$ levels.

Distributions of sparse foliage on individual trees are amorphous and heterogeneous, resulting in different values of void ratio. When choosing measuring patches with 
433

434

435

436

437

438

439

440

441

442

443

444

445

visibly dense foliage (no obvious gaps, $V R<10 \%$ ), it is easy to control the measuring errors. For most of the trees in tests, $V R \approx 5 \%$, while the observed spectral transflectance between the measuring patches and the background noise signal is usually less than $30 \%$ ( $\left.\tau R_{\text {meas_patch }}-\tau R_{\text {meas }} \leq 30 \%\right)$, it implies that the absolute measurement error of the transflectance is below 3\% using equation (9). In this sense, background noise in the transflectance measurement with visibly dense foliage can be disregarded.

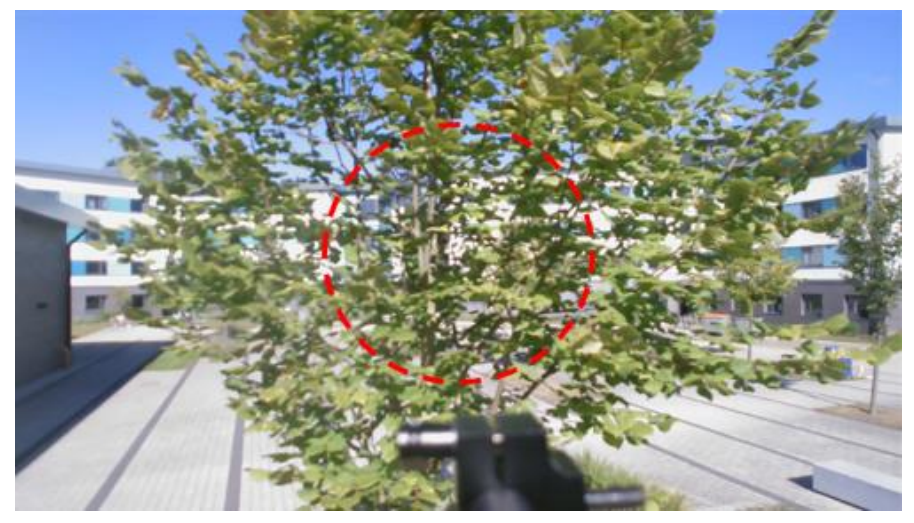

(a) Viewing vision (circle in red dashed line) of the tree crown transflectance measurement in the SAz direction

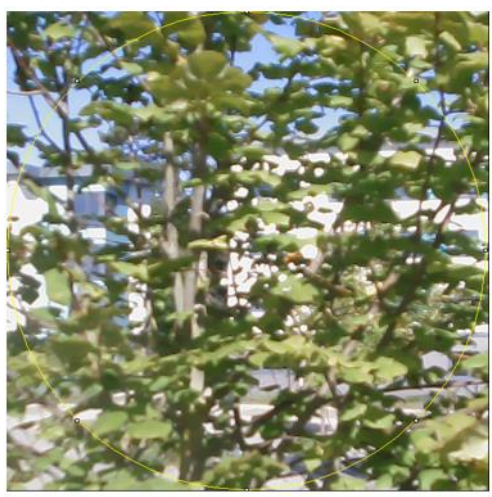

Original image

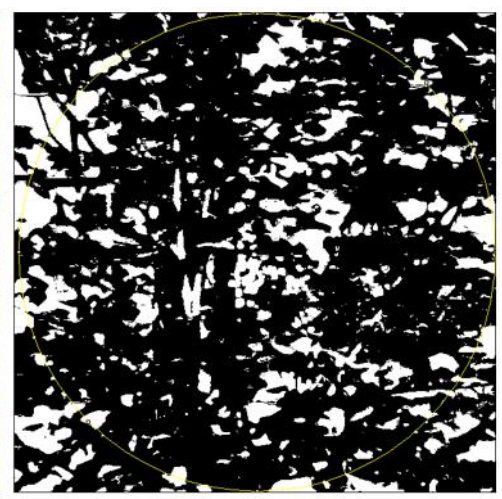

Adjusted by ImageJ software Void ratio: $V R=23.3 \%$

(b) Void ratio of gaps in the viewing vision determined by the Image J software 


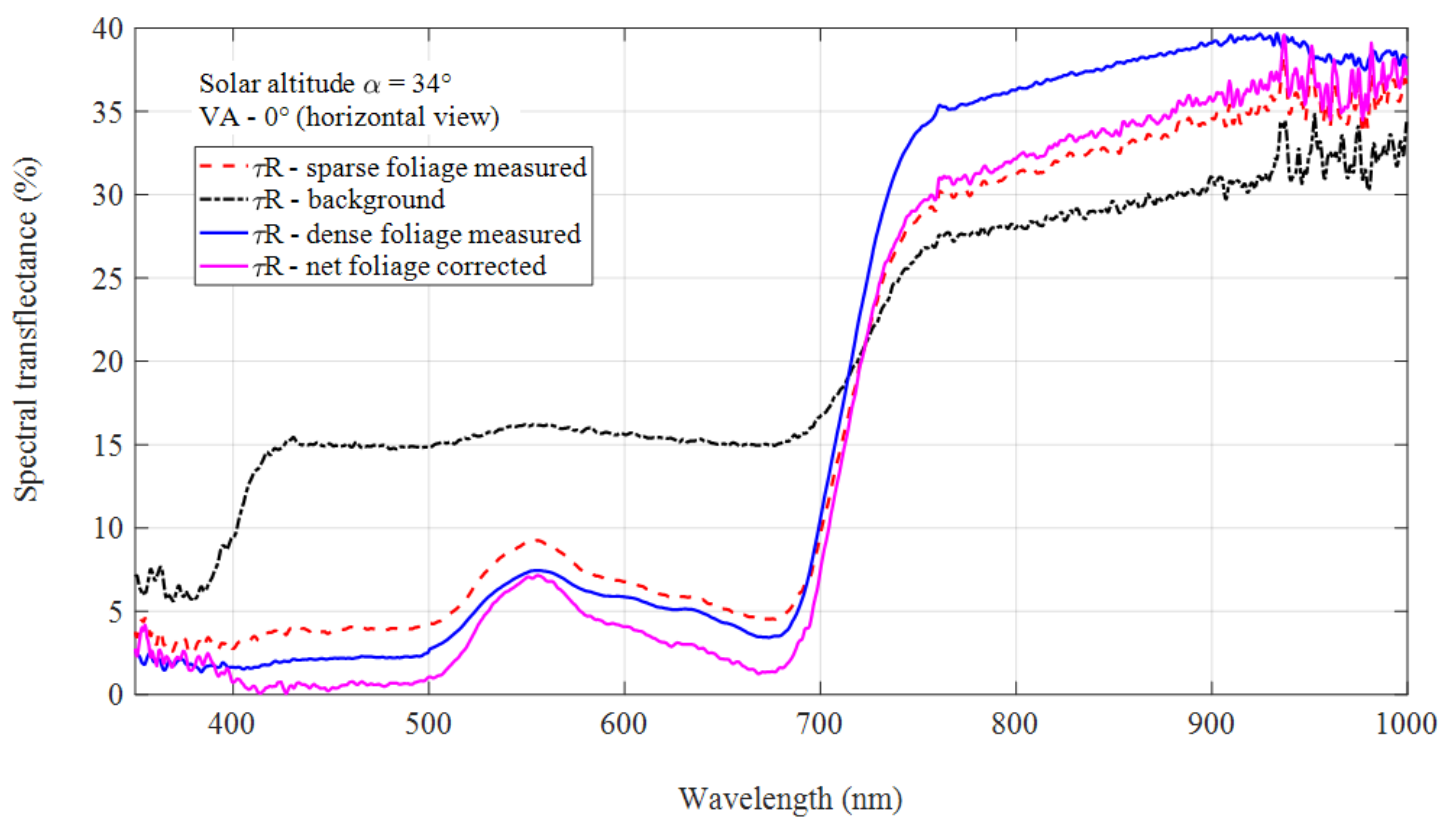

(c) Net transflectance of foliage excluding gaps compared to measured transflectance

Figure 5. Tree crown transflectance of a measuring patch with sparse foliage and gaps in a Tilia platyphyllos and estimation of the background noise impact with $\alpha=34^{\circ}$.

\subsubsection{Impact of concave and convex shapes in crown foliage}

It was found that concave crown contours decreased the $\tau R$ levels, while the convex contours maximised the $\tau R$ levels in various tree species. Take the in-situ test of a 5.5 $\mathrm{m}$ Sequoiadendron giganteum tree as an example. Figure 6(a) shows the $\tau R$ measurement of the tree at different heights in the SAz direction $\left(\alpha=37^{\circ}\right)$ with or without concave shapes in the measuring patches. Viewing vision of the fiber-optic tip in tests (red circles in dashed lines represent the vision) was shown in Figure 6(b). Maximum $\tau R$ appeared at $1.8 \mathrm{~m}$ height nearly without concave shapes in the measuring patch, while the minimum $\tau R$ appeared at $2.5 \mathrm{~m}$ height with concave shapes accounting for approximately half of the area of the viewing vision, and the $\tau R$ at other heights with concave shapes of different extents fell in between. Foliage gaps 


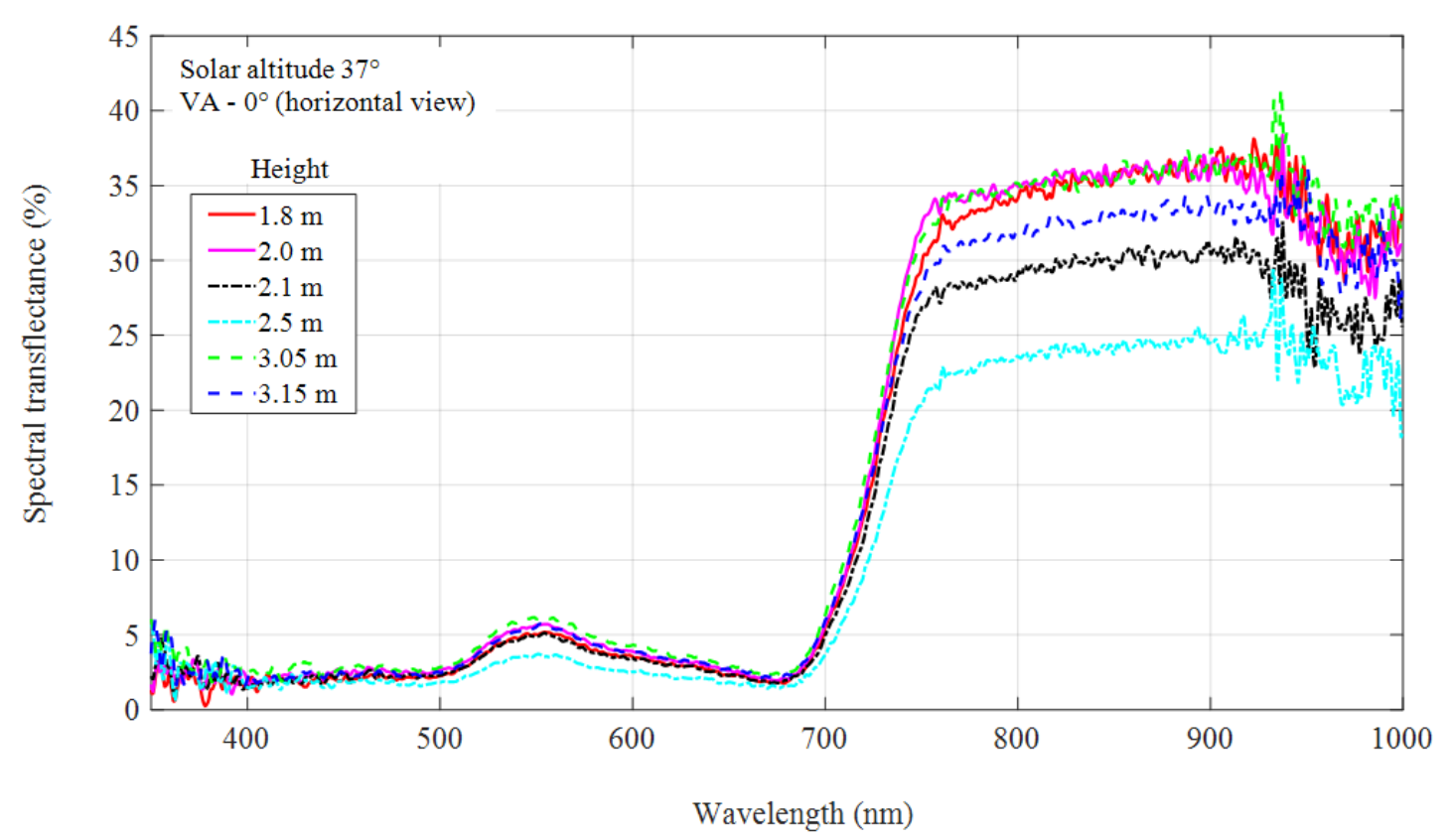

471

472 were rather small compared to the area of concave shapes in these cases. As sunlight was captured by concave shapes in the measuring patches, the concave shapes degraded $\tau R$ levels to different extents depending on the specific scenarios. When the center of the viewing vision (the circles in Figure 6(b)) deviated from the concave shapes and the ratio of concave shapes was not big, it only slightly degraded the $\tau R$ (see $\tau R$ spectra at heights of $2.0 \mathrm{~m}$ and $2.1 \mathrm{~m}$ in Figure 6(a)). It implies that received light of the fiberoptic tip is not evenly contributed by the viewing vision. 


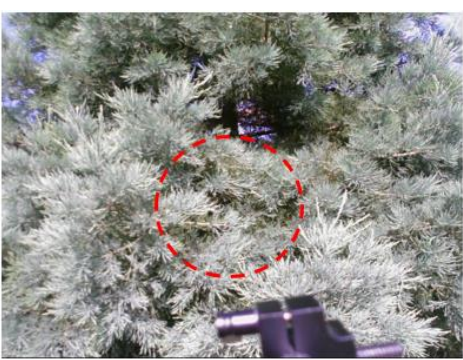

$1.8 \mathrm{~m}$ height

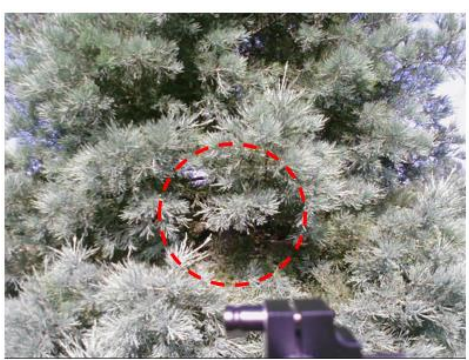

$2.5 \mathrm{~m}$ height

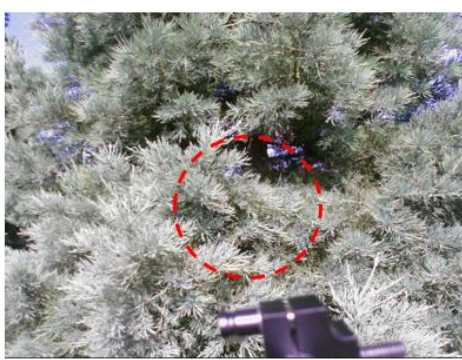

$2.0 \mathrm{~m}$ height

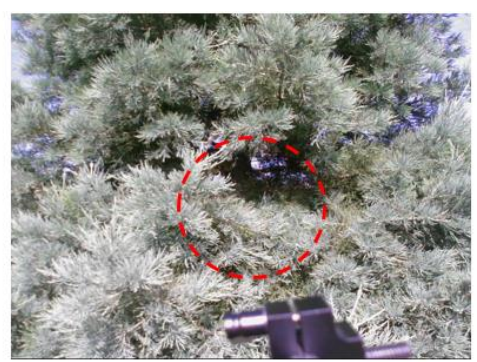

$2.1 \mathrm{~m}$ height

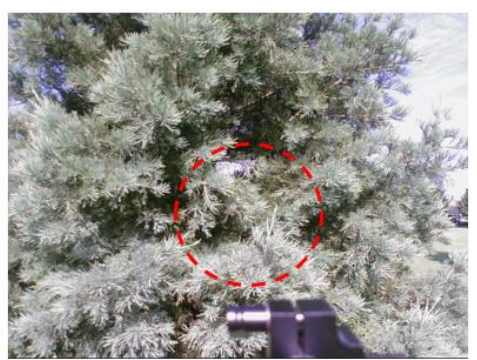

$3.15 \mathrm{~m}$ height

The impact of sparse foliage with gaps and concave crown shapes on the transflectance is complicated and heterogeneous, and different trees within a species do not share a common feature of local foliage distributions. Hence, it is preferable to avoid sampling measuring patches that exhibit sparse foliage with gaps and concave contours when collecting data for statistical analysis of radiative performance levels of various tree species. Any such patches are likely to be identified as outliers in transflectance sampling. Generally, it is possible to find measuring patches on trees with relatively dense foliage and without visible concave contours. In our field tests of 10 tree species, even for the tree species with the sparsest foliage (Betula pendula - silver birch) it was 
488

489

490

491

492

493

494

495

496

497

498

499

500

501

502

503

504

505

506

507

508

509

easy to find dense foliage for tests without gaps in foliage and concave contours using the naked-eye.

\subsubsection{Impact of solar altitude on tree crown $\tau R$}

To explore the relationship between change in transflectance and solar time, solar altitude $(\alpha)$ was recorded when sampling the transflectance, referring to a website [72]. Figure 7 shows the $\tau R$ spectra in the frontal sunlit area of a Carpinus betulus tree at different solar altitudes. It suggests that the tree crown transflectance increases as solar altitude rises. In further data analysis, it is found that the $\tau R$ in the IR region tends to be linearly correlated with $\alpha$, while no obvious variation is observed in the VIS region due to a low $\tau R$ level. To dig out laws of change of $\tau R$ versus $\alpha$, mean transflectance in the wavelength range of $800-900 \mathrm{~nm}\left(\tau R_{\text {mean,800-900 }}\right)$ was taken as an indicator, because tree crown $\tau R$ spectra usually tend to be flat and hold the maximum spectral transflectance in the NIR wavelength range of $800-900 \mathrm{~nm}$. Figure 8 shows the $\tau R_{\text {mean,800-900 }}$ of the Carpinus betulus trees in terms of the tree crown $\tau R$ in the frontal sunlit area linearly correlated with solar altitude $\alpha$. The rule of change of IR transflectance versus solar altitude allows making a benchmark for intraspecies and interspecies comparisons in section 4.4 , by converting $\tau R$ spectra at different solar altitudes into equivalent $\tau R$ spectra at the same solar altitude. Figure 9 shows the linear fitting results of the $\tau R$ spectra in the frontal sunlit area of the Carpinus betulus trees varying with solar altitude in the wavelength range of $350-1000 \mathrm{~nm}$. 


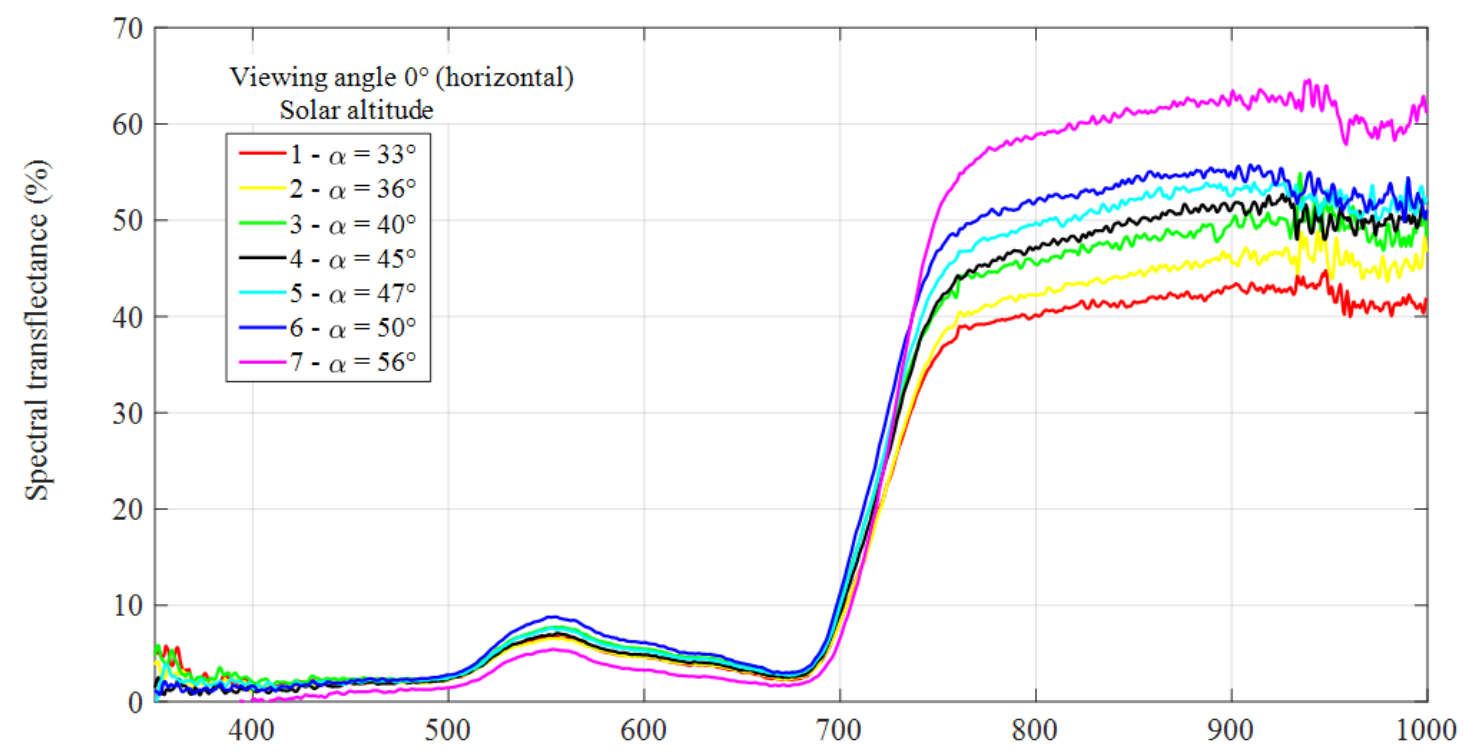

Wavelength (nm)

512 Figure 7. Transflectance spectra of tree crown surfaces for a Carpinus betulus tree in 513 the frontal sunlit area at different solar altitudes $(\alpha)$.

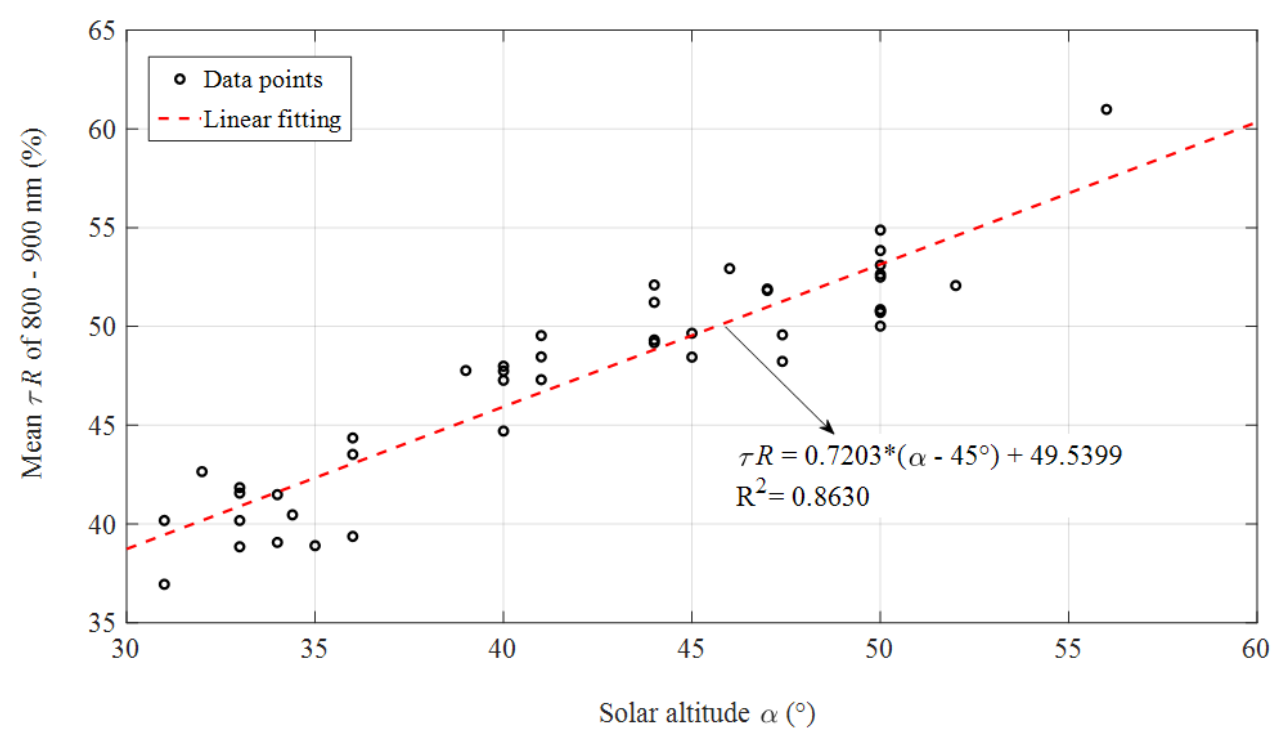

Figure 8. Linear fitting of the $800-900 \mathrm{~nm}$ mean transflectance $\left(\tau R_{\text {mean,800-900 }}\right)$ with the solar altitude $\alpha$ for individual Carpinus betulus trees using samples in the frontal sunlit area of trees. 


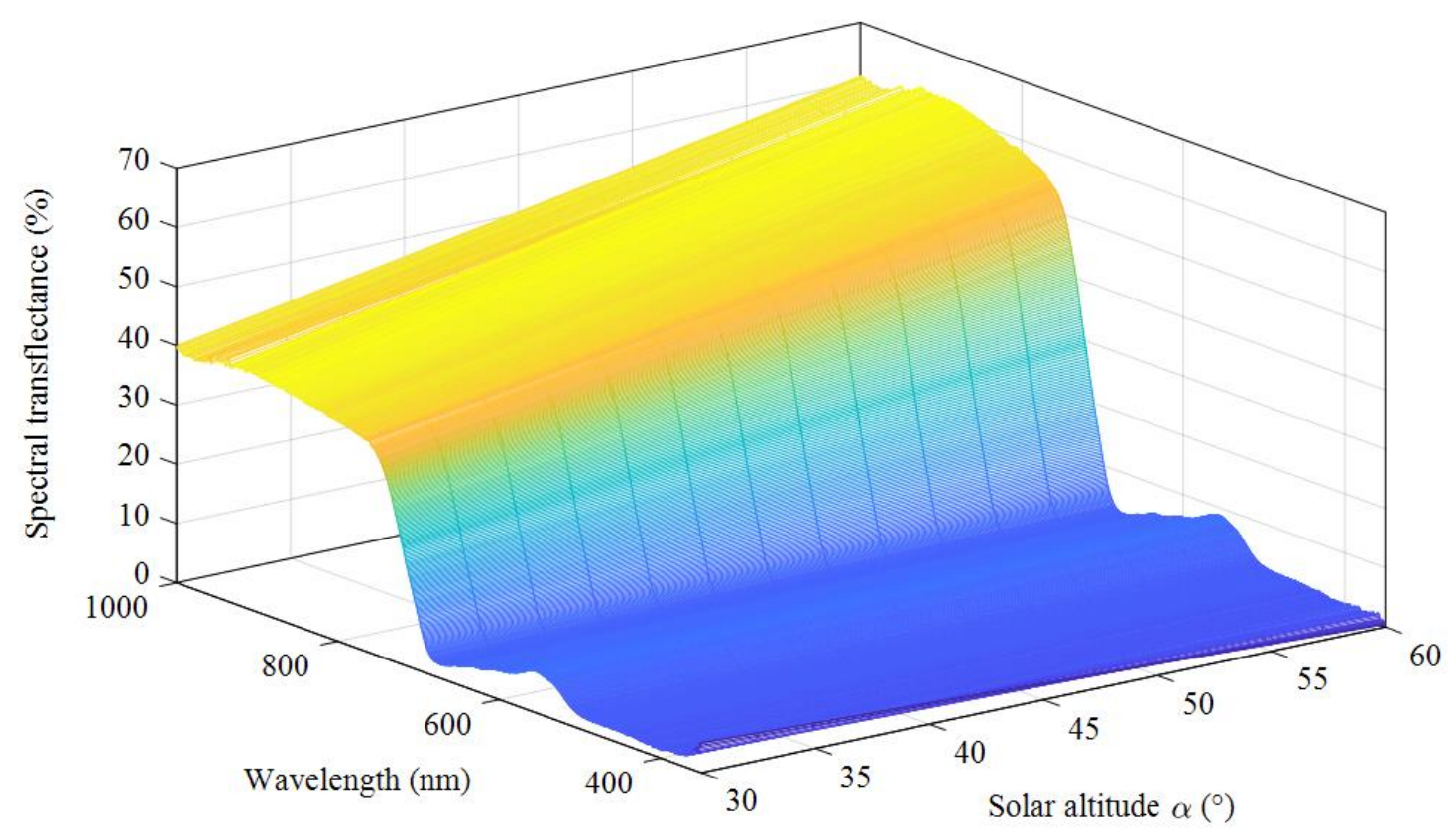

521

(a) 3D plot

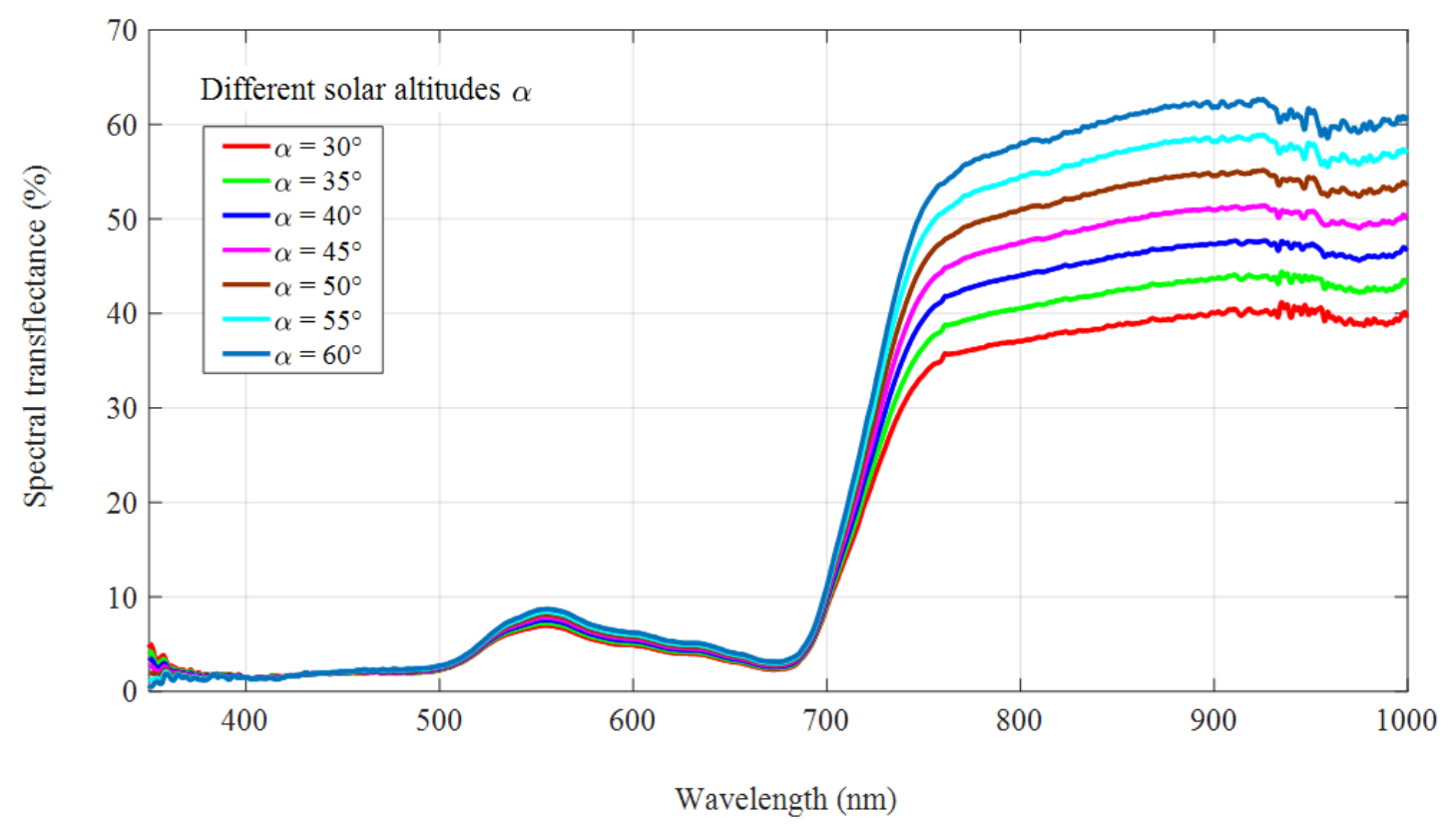

(b) 2D plot with discrete values of solar altitude

524 Figure 9. Linear fitting of tree crown transflectance spectra in the frontal sunlit area of

525 Carpinus betulus trees varying with solar altitude in the wavelength range of 350-1000 nm. 
In all the ten species measured, it was found that the tree crown IR transflectance in the frontal sunlit area of trees for a specific species was linearly correlated with solar altitude on sunny days. The coefficients of determination $\left(R^{2}\right)$ in most cases of linear fittings were above 0.76, except the tree species Betula pendula and Aesculus hippocastanum. It was presumed that the low $R^{2}$ in the fitting of Betula pendula was mainly due to apparently sparse leaf density of the species. As to the species Aesculus hippocastanum, the low $R^{2}$ in the fitting was attributed to the development of horse chestnut leaf-miner throughout the summer [73]. Horse chestnut leaf-miner caused brown blotch mines to develop between the leaf veins, resulting in a degradation of the transflectance spectrum especially in $750-900 \mathrm{~nm}$ wavelength range.

\subsection{Spatial distribution of transflectance around tree crowns}

As argued in our earlier work [62], transmission and reflection spectra at the leaf level were similar between trees (similar results also shown in section 4.1), while substantial variations were found in tree crown $\tau R$ (transflectance) spectra due to crown structural difference and solar time. To explore spatial distribution rules of the radiative performance across a tree crown, $\tau R$ spectra in typically horizontal and vertical loops around the tree crowns have been examined.

\subsection{1 $\tau R$ Distribution in a horizontal loop}

Four orientations in a horizontal plane were concerned, as shown in Figure 10(a) with the $7.0 \mathrm{~m}$ height Carpinus betulus tree. A single vertical reference plane in the solar 
550

551

552

553

554

555

556

557

558

559

560

561

562

563

564

565

566

567

568

569

570

azimuth (SAz) direction was chosen for $\tau R$ spectra measurements in the four horizontal directions $\left(\mathrm{SAz} ; \mathrm{SAz}+90^{\circ}\right.$ clockwise; $\mathrm{SAz}+180^{\circ}$ clockwise; $\mathrm{SAz}+270^{\circ}$ clockwise). The test sequence was implemented at $4.4 \mathrm{~m}$ height during 9:44-9:47 am (British Summer Time) on the sunny day of 20th August 2019 with solar altitude $\alpha=$ $33^{\circ}$. Figure 10(b) shows measured $\tau R$ spectra in the four horizontal directions. To display the transflectance distribution in different directions intuitively, the $\tau R_{\text {mean,800-900 }}(800-900 \mathrm{~nm}$ mean transflectance) was taken as an indicator again. Figure 10 (c) plots the distribution of $\tau R_{\text {mean,800-900 }}$ in the horizontal loop in polar coordinates, where the radius from the origin ' 0 ' to the point represents the value of

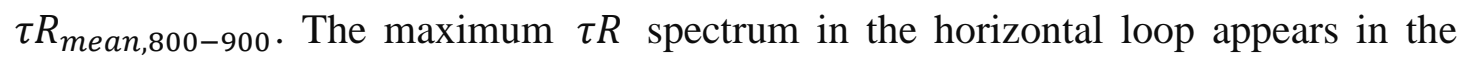
frontal sunlit area of the tree, followed by $\mathrm{SAz}+90^{\circ}$ and $\mathrm{SAz}+270^{\circ}$ clockwise directions. The tree crown $\tau R$ on the shade side $\left(\mathrm{SAz}+180^{\circ}\right.$ clockwise) has the lowest $\tau R$ level. It seems that the $\tau R_{\text {mean, } 800-900}$ in the $\mathrm{SAz}+90^{\circ}$ and $\mathrm{SAz}+270^{\circ}$ directions tends to be spatially symmetric. This was because no obvious concave contours were viewed on the measuring patches in both directions. We have observed scenarios of nonsymmetric distribution in the two directions in an Acer campestre tree during 10:3510:40 am on 27 th June 2019 , as shown in Figure 11 . The $\tau R_{\text {mean,800-900 }}$ in the $\mathrm{SAz}+270^{\circ}$ clockwise direction was much lower than that in the $\mathrm{SAz}+90^{\circ}$ clockwise direction, as apparent concave contours appeared in the $\mathrm{SAz}+270^{\circ}$ clockwise direction, resulting in a reduction of the $\tau R$ level. 


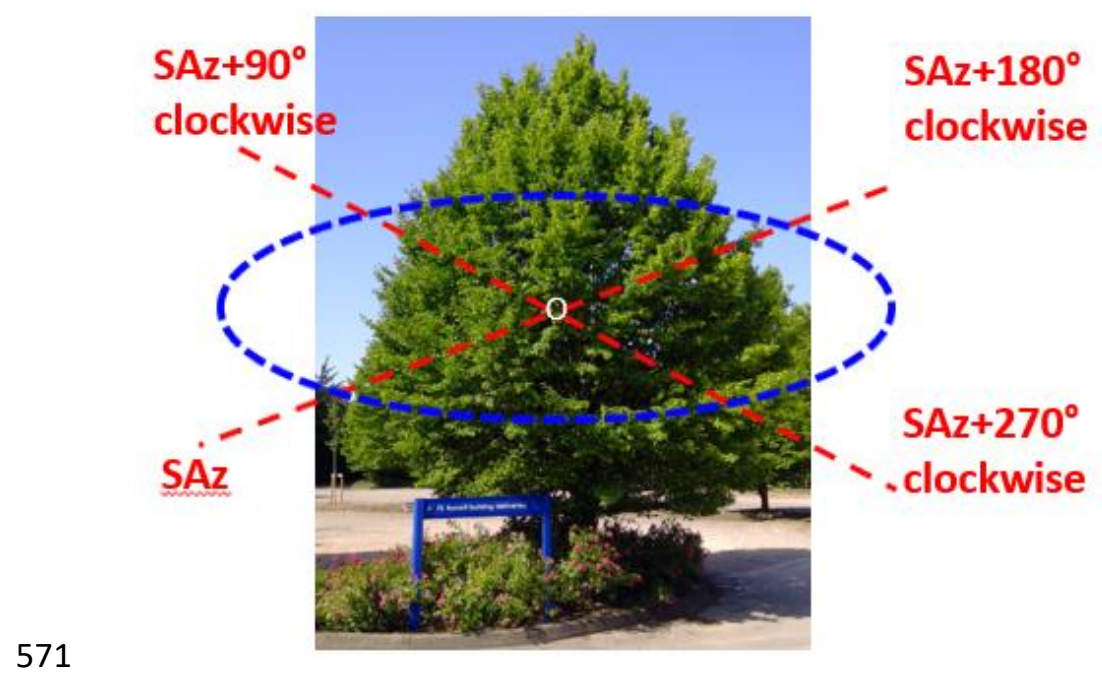

572

(a)

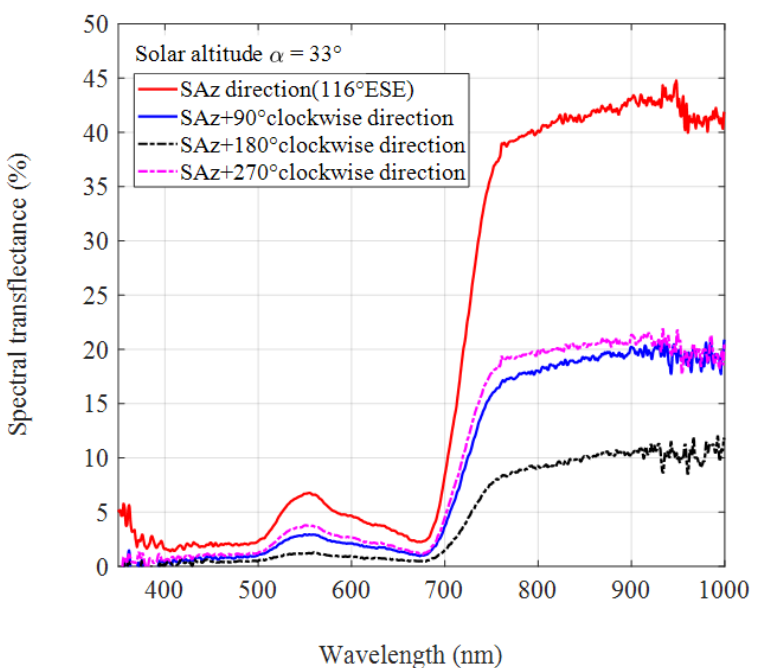

(b)

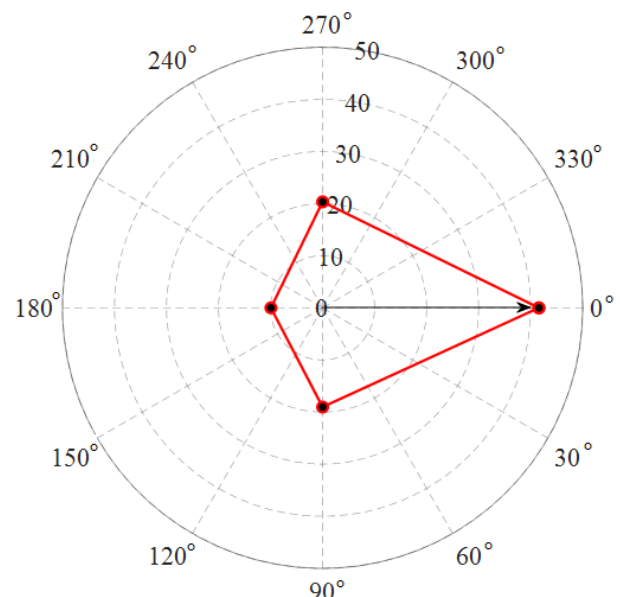

800 - $900 \mathrm{~nm}$ mean transflectance (\%)
573

574

575

576

577

578

579

580 clockwise). 


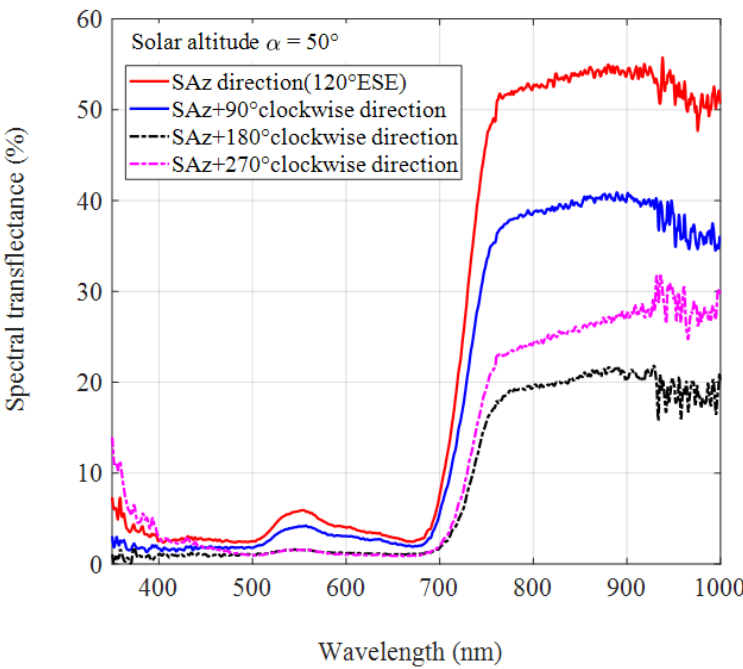

(b)

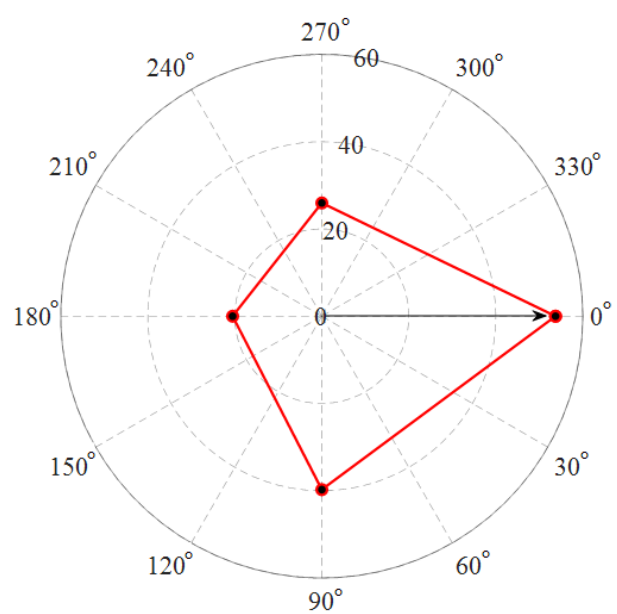

$800-900 \mathrm{~nm}$ mean transflectance (\%)

(c)
584

585

586

587

588

589

590

591

592

593

594

595

596

597

598

\subsection{2 $\tau R$ Distribution in a vertical loop around the tree crown and aligned with}

the solar azimuth direction

Two typical vertical loops around the tree crown were chosen in determining distribution of tree crown $\tau R$ (transflectance) in vertical planes. One was a vertical loop aligned with the SAz (solar azimuth) direction. The other was a vertical loop perpendicular to the SAz direction (see next section 4.3.3). Figure 12(a) sketches 10 sampled directions distributed in the vertical loop aligned with the SAz in the $7.0 \mathrm{~m}$ height Carpinus betulus tree. Figure 12(b) gives measuring results of the $\tau R$ spectra in the 10 sampled directions with the tree at $\alpha=35^{\circ}$. The distribution of $\tau R_{\text {mean,800-900 }}$ is delineated in Figure 12(c). It indicates that points '1', '2', '3', '4', ' 5 ' in the frontal sunlit area of the tree have high $\tau R$ levels, while other points hold 
relatively low $\tau R$ levels. Especially, point ' 9 ' beneath the tree has the minimum $\tau R_{\text {mean,800-900 }}$ value (only 6.9\%). Additionally, the point ' 4 ' representing the case of fiber-optic tip tilted $60^{\circ}$ looking downwards has the maximum $\tau R_{\text {mean,800-900. The }}$ values of $\tau R_{\text {mean,800-900 }}$ in the fontal sunlit area at different viewing angles $(\mathrm{VA}=$ $30^{\circ}, 45^{\circ}, 60^{\circ}$ and $90^{\circ}$ looking downwards) varied with solar time, as it was found that the maximum value did not maintain in the direction of $\mathrm{VA}=60^{\circ}$ downwards. Figure 13 gives the vertical loop distribution of the Carpinus betulus tree at the solar altitude $\alpha=49^{\circ}$. Comparing the horizontal samples of point ' 1 ' in Figures 12(c) and 13, it confirmed that the tree crown $\tau R$ at a higher solar altitude $\left(\alpha=49^{\circ}\right)$ is higher than that at a lower case $\left(\alpha=35^{\circ}\right)$. Furthermore, the strongest tree crown transflection was found primarily towards sky on the sunlit side of trees rather than towards zenith. Infrared transflection towards surrounding buildings and pedestrians is substantial. The finding provides insights on understanding radiative interactions between urban trees and surrounding built environments.

Additionally, it is noteworthy that tree crown morphology is linked to the space of the frontal sunlit area of trees, implying that tree morphology affects distributions of the tree crown $\tau R$. 

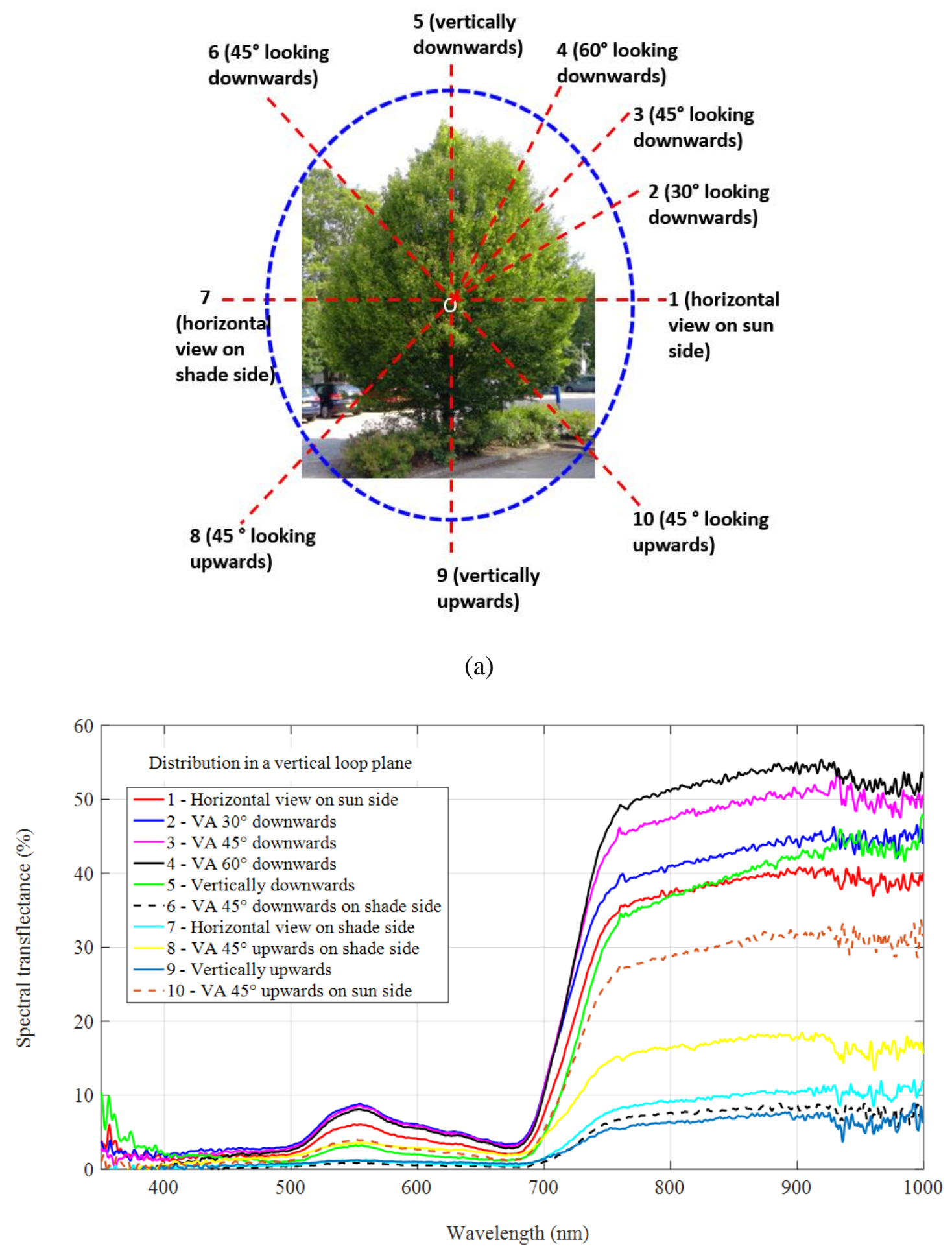

(b) 


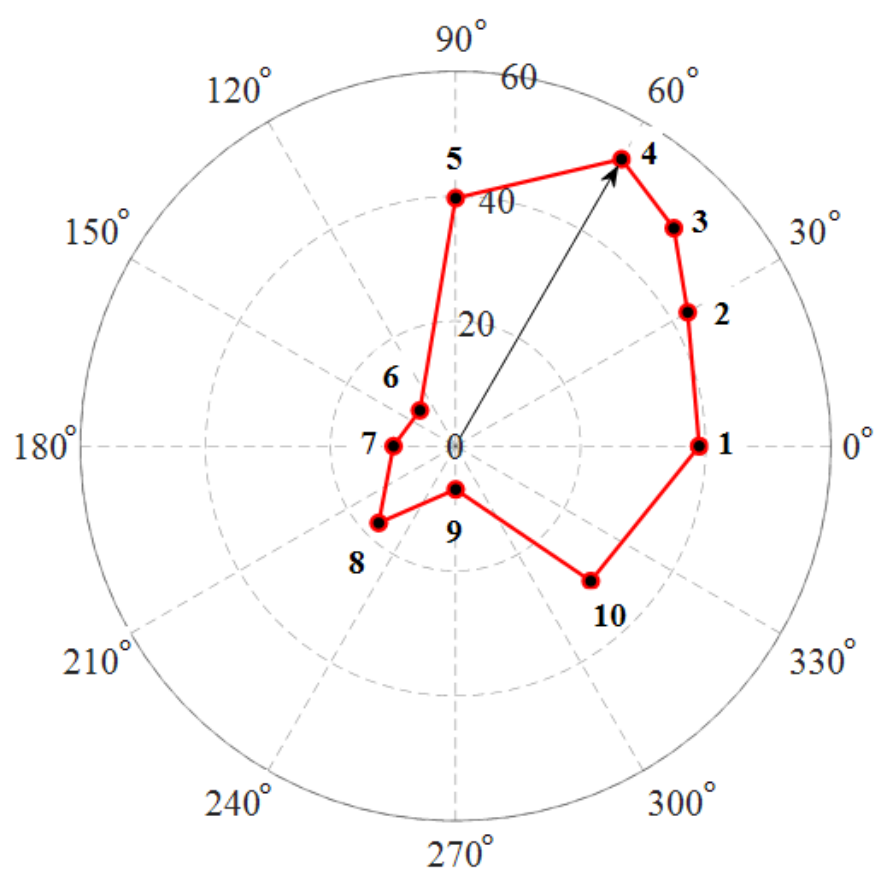

621 800 - $900 \mathrm{~nm}$ mean transflectance (\%)

623 Figure 12. Transflectance $(\tau R)$ spectra distribution of a Carpinus betulus tree at $\alpha=$ $62435^{\circ}$ in a vertical loop around tree crown and aligned with the solar azimuth (SAz) 625 direction (a) sketch of 10 sampled directions in the vertical loop; (b) measured $\tau R$ 626 spectra; (c) distribution of $\tau R_{\text {mean,800-900 }}$ in polar coordinates. 


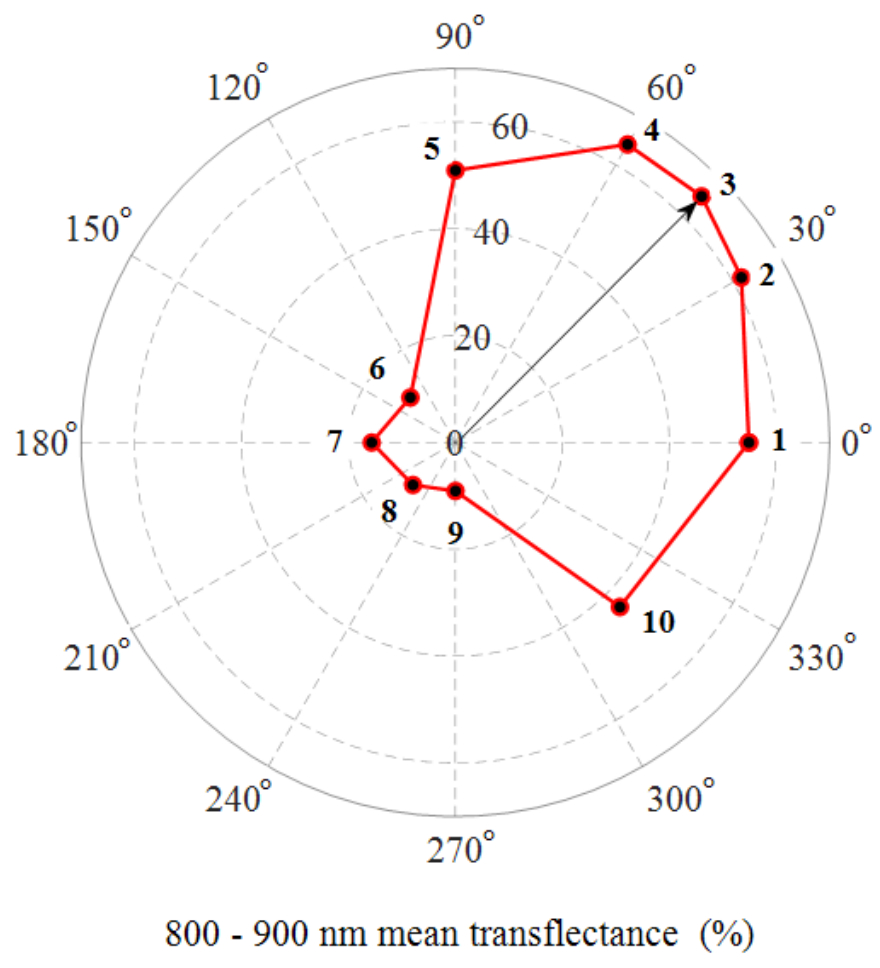

628

629 Figure 13. $\tau R_{\text {mean }, 800-900}$ distribution of a Carpinus betulus tree in polar coordinates

630 at $\alpha=49^{\circ}$ in a vertical loop around the tree crown and aligned with the SAz direction

631

4.3.3 $\tau R$ Distribution in a vertical loop around the tree crown and perpendicular 633 to the solar azimuth direction

The vertical loop perpendicular to the SAz direction was sampled in 8 directions, as betulus tree in the 8 sampled directions at $\alpha=37^{\circ}$, while Figure 14(b) plots distribution of $\tau R_{\text {mean,800-900 }}(800-900 \mathrm{~nm}$ mean) in polar coordinates. The maximum $\tau R$ appears at point ' 3 ' (vertically downwards), with $\tau R$ at the other points transflection is towards sky on the sunlit side of trees rather than towards zenith. 


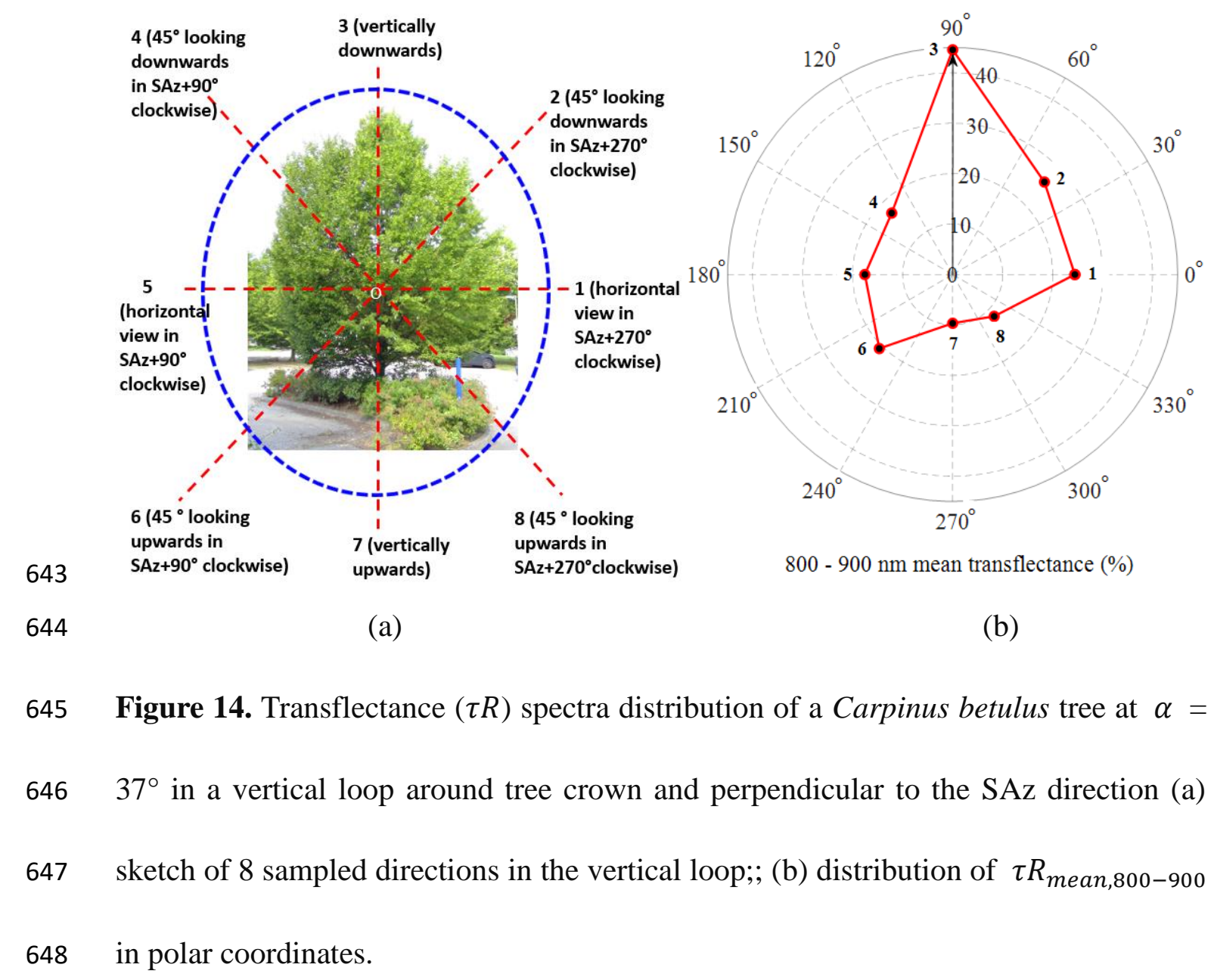

649

650

4.4 Interspecific difference comparison of radiative performance levels

651

4.4.1 Principles of sample selections in estimating statistical mean $\boldsymbol{\tau} R$ spectra of 652 tree species

653 As elucidated in sections 4.2 and 4.3, the impact factors of the tree crown $\tau R$ are diverse, and the spatial distribution of the $\tau R$ in tree crowns is nonuniform and varies

655 with solar altitude. A benchmark is therefore needed to make interspecific comparison.

656 Principles of test sample selections in estimating the statistical mean $\tau R$ spectra of 657 various tree species are stated below:

- Visually dense measuring patches without visible gaps in crown foliage and 
concave crown contours in the viewing vision of the fiber-optic tip were selected. All trees used in the experiment were young adult to mature adult trees. Tree ages were not accounted for - the only requirement was that dense patches of foliage could be located on the tree crowns.

- The $\tau R$ spectra in the frontal sunlit area of trees with vertical reference planes normal to transient solar azimuth (SAz) directions were sampled to examine for statistical mean. 
681

682

683

684

685

686

687

688

689

690

691

692

693

694

695

696

697

698

699

700

701

702

stress on the $\tau R$ was observed. Similarly, no significant effect of different urbanised settings of tested trees (planted on paved/sealed surfaces or on green lawns/parks) on the $\tau R$ was found. Thus, the impact of heat stress and different urbanized settings of trees was not assessed in intraspecific statistical analysis.

\subsubsection{Interspecific difference of infrared radiative performance levels}

Here we use Carpinus betulus as an example to display the process of estimating statistical mean $\tau R$ spectrum within a species. In total, effective $\tau R$ spectrum samples of 9 Carpinus betulus trees were obtained. $\tau R$ spectra of each individual tree were converted to the $\tau R$ spectrum at $\alpha=45^{\circ}$, and were then averaged to get a representative $\tau R$ spectrum for the individual tree. The statistical mean $\tau R$ spectrum of the Carpinus betulus species was estimated by using 9 representative $\tau R$ spectra from 9 individual trees. Representative $\tau R$ spectra of 5-9 trees were obtained for various tree species except the Acer platanoides, as only four individual trees were accessible for the copper Norway maple. Statistical mean $\tau R$ spectra in the frontal sunlit area of the 10 tree species at $\alpha=45^{\circ}$ can be accessed in Appendix $\boldsymbol{A}$.

Figure 15 gathers the mean $\tau R$ spectra and corresponding standard error bands of the 10 species, displaying interspecific performance difference. Table 1 lists statistical $\tau R_{\text {mean,800-900 }}(800-900 \mathrm{~nm}$ mean transflectance) values for the 10 tree species. It suggests that Aesculus hippocastanum and Platanus x acerifolia have the highest levels of IR radiative performance ( $\tau R_{\text {mean,800-900 }}: 0.597 \pm 0.027$ for Aesculus hippocastanum 
703

704

705

and $0.598 \pm 0.011$ for Platanus x acerifolia), followed by Acer platanoides, Quercus robur, Acer campestre, Tilia platyphyllos, Carpinus betulus (fastigiate hornbeam) and Acer x freemanii successively on moderate levels ( $\tau R_{\text {mean,800-900 }}: 0.475-0.540$ and standard error within \pm 0.014$)$. Betula pendula has the second lowest levels of IR radiative performance $\left(\tau R_{\text {mean }, 800-900}: 0.439 \pm 0.009\right)$, presumably due to the fact that this native British tree species is usually observed with a small leaf size and apparently sparse leaf density. Sequoiadendron giganteum has the minimum levels of IR radiative performance $\left(\tau R_{\text {mean }, 800-900}: 0.398 \pm 0.009\right)$, resulting from the minimum leaf size (needle leaves) among the tested species.

Figure 16 shows images of tree leaves for the tested species corresponding to the radiative performance levels. Interesting is that, the tree species with large-sized leaves (such as Platanus x acerifolia, Aesculus hippocastanum) lead to maximum radiative performance levels, followed by the tree species with moderate-sized leaves (e.g. Acer platanoides, Quercus robur, Acer campestre, Tilia platyphyllos). Carpinus betulus has a leaf size smaller than other tree species on the moderate levels of radiative performance, resulting in a slightly lower performance level than the others except Acer $\mathrm{x}$ freemanii. Although the leaf size of Acer $\mathrm{x}$ freemanii seems to be close to that of Quercus robur and Acer campestre, branching structure of its leaves degrades its radiative performance level. From this perspective, each individual leaf of Acer $\mathrm{x}$ freemanii can be viewed as three leaflets which have similar leaf sizes as the Carpinus betulus leaves, resulting in the same radiative performance level as the latter. 

the minimum radiative performance level. It reveals that interspecific difference of

727 infrared radiative performance levels strongly depends on leaf size when visibly dense

728 foliage (no visible gaps and concave shapes in crown foliage) is observed on the tree

729 crown contours. The finding confirms the viewpoint in [74] that species average leaf 730 size is the most important determinant of self-shading that affected light capture. It 731 provides insights on species selection for heat stress mitigation in urban microclimates.

732 The impact of leaf size implies that disregarding tree ages (young or old) in sampling 733 visually dense measuring patches (see 4.4.1) is appropriate, as mature trees of a specific-species tend to have reasonably similar leaf shape and leaf size.

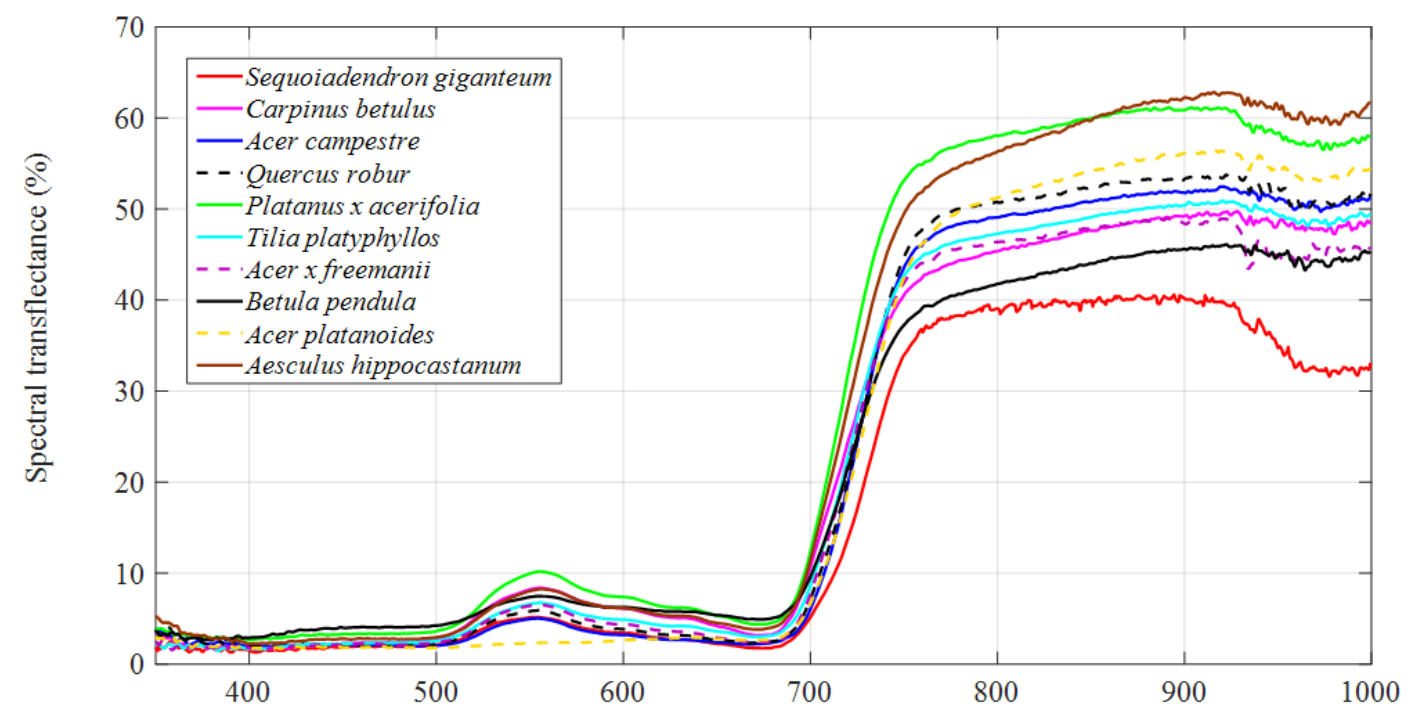




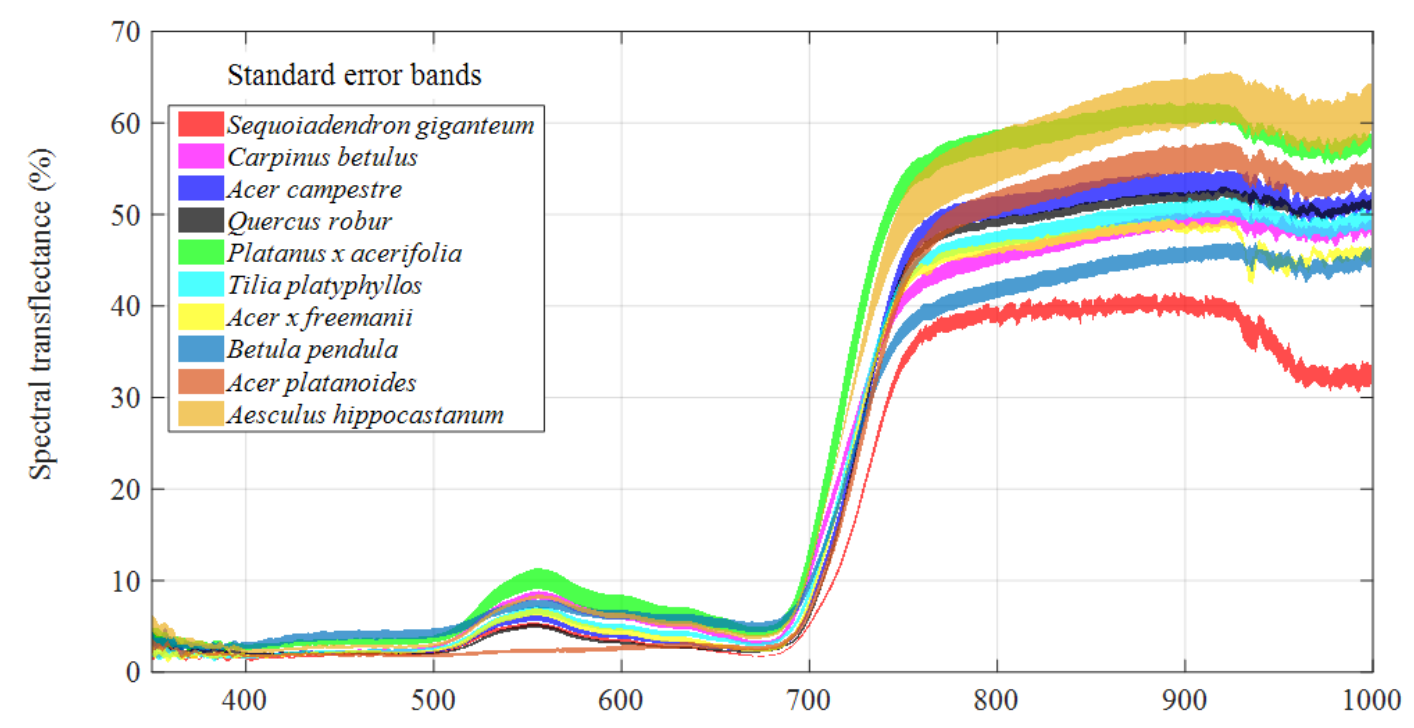

$737 \quad(b)$

Wavelength (nm)

738 Figure 15. Interspecific radiative performance difference of ten tree species planted in

739 the UK in terms of equivalent $\tau R$ spectra at $\alpha=45^{\circ}$ (a) statistical mean $\tau R$ spectra;

740 (b) standard mean error bands.

741

742 Table 1. Statistical $\tau R_{\text {mean,800-900 }}$ for ten tree species

\begin{tabular}{lll}
\hline Tree species & $\begin{array}{l}\tau R_{\text {mean }, 800-900} \\
(\%)\end{array}$ & $\begin{array}{l}\text { Standard mean } \\
\text { error }(\%)\end{array}$ \\
\hline Sequoiadendron giganteum (Giant sequoia) & 39.8 & \pm 0.9 \\
\hline Carpinus betulus (Fastigiate hornbeam) & 47.5 & \pm 0.9 \\
\hline Acer campestre (Field maple) & 52.2 & \pm 1.2 \\
\hline Quercus robur (English oak) & 50.7 & \pm 0.5 \\
\hline Platanus x acerifolia (London plane) & 59.8 & \pm 1.1 \\
\hline Tilia platyphyllos (Large-leaved lime) & 49.0 & \pm 0.9 \\
\hline Acer x freemanii (Autumn blaze maple) & 47.8 & \pm 0.6 \\
\hline Betula pendula (Silver Birch) & 43.9 & \pm 0.9 \\
\hline Acer platanoides (Copper Norway maple) & 54.0 & \pm 1.4 \\
\hline Aesculus hippocastanum (Horse chestnut) & 59.7 & \pm 2.7 \\
\hline
\end{tabular}


Tree crown

Transflectance levels

High

Low
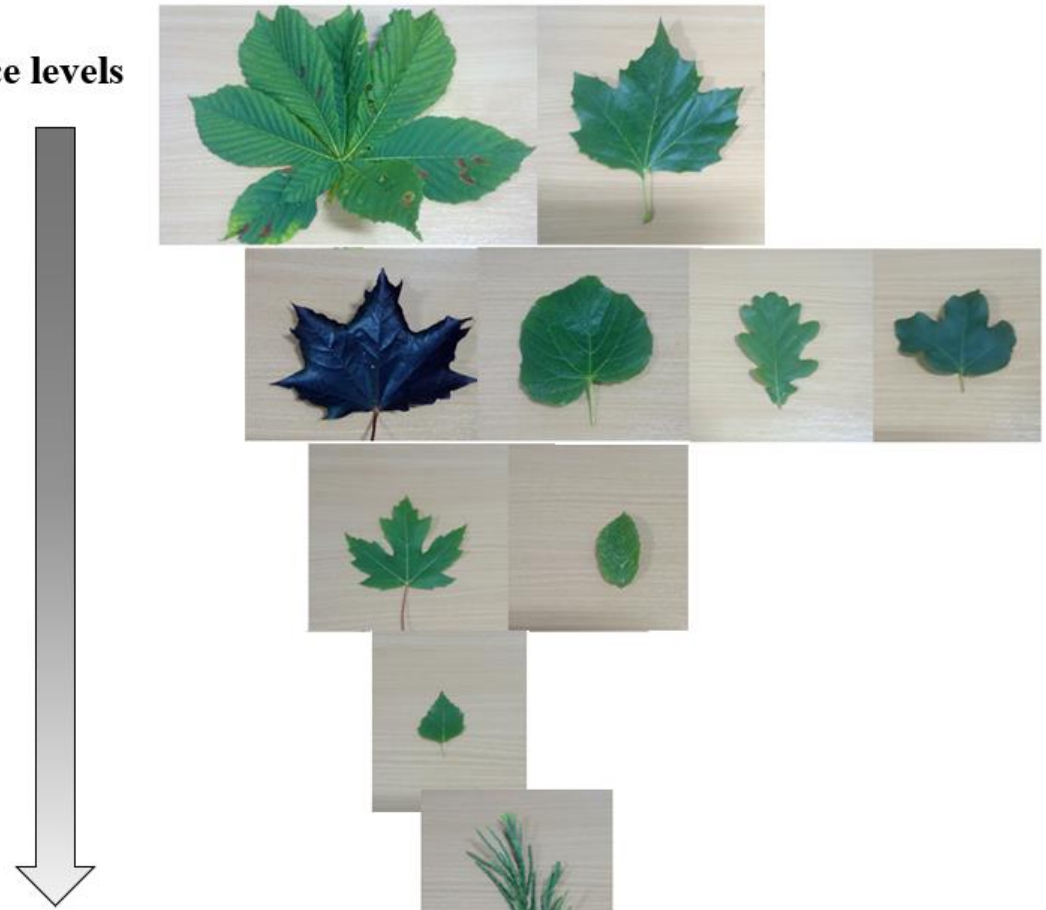

Figure 16. Radiative performance levels of multiple tree species classified by leaf size.

4.4.3 Identification of intraspecific and interspecific differences in canopy transflectance by PCA

At the scale of crown patches significant differences in transflectance were observed between species, and these corresponded to different biological and spectral properties. PCA of the $5 \mathrm{~nm}$ spectral bands $(\mathrm{n}=130$ per tree crown) collected from 67 individual trees across 10 species revealed significant interspecific differences in crown transflectance for the $350-1000 \mathrm{~nm}$ range. The first two PCA axes explained $86.9 \%$ of the variance in spectral profiles and were significantly correlated with different canopy transflectance properties (see Table 2).

Table 2. Relationship between first five PCA axes and bands of canopy transflectance 
in the $350-1000 \mathrm{~nm}$ range across 67 individual trees drawn from 10 species

\begin{tabular}{lllll}
\hline Axis & $\begin{array}{l}\text { Variance } \\
\text { explained }\end{array}$ & $\begin{array}{l}\text { Cumulative } \\
\text { variance }\end{array}$ & $\begin{array}{l}\text { Positive correlation } \\
(\boldsymbol{r})\end{array}$ & $\begin{array}{l}\text { Negative correlation } \\
(\boldsymbol{r})\end{array}$ \\
\hline 1 & $54.5 \%$ & $54.5 \%$ & All except $370-375 \mathrm{~nm}$ & \\
\hline 2 & $32.4 \%$ & $86.9 \%$ & $735-1000 \mathrm{~nm}$ & $395-705 \mathrm{~nm}$ \\
\hline 3 & $7.2 \%$ & $94.1 \%$ & $350-485 \mathrm{~nm}$ & $525-615 \& 695-735 \mathrm{~nm}$ \\
\hline 4 & $2.6 \%$ & $96.7 \%$ & $350-400 \mathrm{~nm}$ & \\
\hline 5 & $1.5 \%$ & $98.2 \%$ & & $350-355 \mathrm{~nm}$ \\
\hline
\end{tabular}

Increasing transflectance in the $350-1000 \mathrm{~nm}$ range corresponded to axis 1 of the PCA and was the most explanatory factor contributing to species differences (Table 2). The strongest correlation to axis 1 was found in the transition between VIS and NIR; largeleaved species (Platanus x acerifolia and Aesculus hippocastanum) were positively associated with this axis, whereas the only conifer (Sequoiadendron giganteum) was negatively associated (Species $R^{2}=0.731 ; P<0.001$; Figure 17). Species were further sub-divided by their opposing interactions with NIR and components of VIS. Axis 2 corresponded with increasing NIR and decreasing VIS (violet, blue, yellow and orange) transflectance (Table 2); Acer platanoides and Quercus robur were positively associated with this second axis, whereas Sequoiadendron giganteum and Betula pendula were negatively associated (Species $R^{2}=0.663 ; P<0.001 ;$ Figure 17). These results show that interspecific differences between the transflectance profiles of 772 commonly planted tree species are readily measurable and reveal key differences 773 between species that can alter radiative performance in urban areas. As noted by 774 Cavender-Barres et al. [70], leaf spectra can be considered as an integrated measure of 775 phenotype; hence, further research into the impacts of environmental stress on canopy 776 transflectance could help in understanding the likely consequences of climate change 
777 for urban areas, in terms of the impact on radiative performance and energy balance.

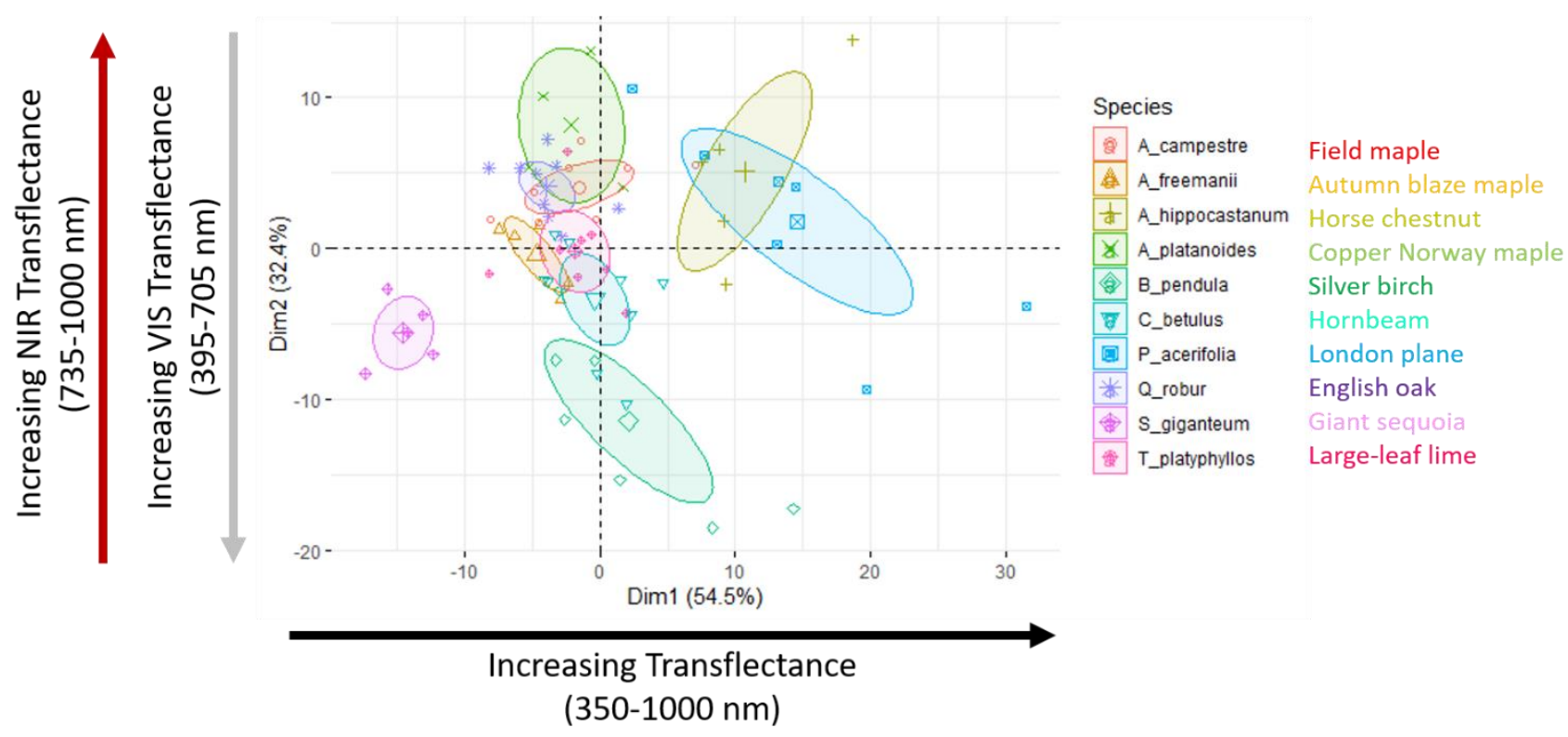

779

Figure 17. PCA of crown transflectance spectra for axes 1 and 2 displaying differentiation between species and spectral properties correlated with each axis. Polygons represent $95 \%$ confidence interval for each species.

Furthermore, PERMANOVA using distance indices supported significant interspecific variation in crown transflectance (Species, 999 permutations: Pseudo- $F$ df $9,57=14.3$; $\left.R^{2}=0.694 ; P=0.001\right)$. Although variability in crown transflectance was observed within species, examination of the homogeneity of multivariate dispersion indicated that intraspecific variance (i.e. variance within species) was not significantly different between species (Species, 999 permutations: $\left.F_{\mathrm{df} 9,57}=1.86 ; P=0.077\right)$. Hence, crown transflectance values were relatively similar within species, and the degree of multivariate variability within species was relatively similar between species. However, this observation was based on collecting spectral data from canopy patches with a 
793

794

795

796

797

798

799

800

801

802

803

804

805

806

807

808

809

810

811

812

813

814

consistent, generally convex, coverage of leaves and avoiding gaps or concave patches.

Therefore, intraspecific differences are expected to be strongly influenced by their unique life-history, including interactions with the biotic/abiotic environment and local government landscaping and management decisions.

\section{Conclusions}

Based on a tree crown spectroscopy measurement method established earlier, substantial in-situ tests of radiative performance of 10 tree species have been implemented in terms of the tree crown transflectance $(\tau R)$. Spatial distribution rules of the $\tau R$ across tree crowns were identified. Infrared radiative performance difference of the 10 tree species (Sequoiadendron giganteum, Carpinus betulus, Acer campestre, Quercus robur, Platanus x acerifolia, Tilia platyphyllos, Acer x freemanii, Betula pendula, Acer platanoides, Aesculus hippocastanum) commonly planted in the UK was statistically determined in terms of $\tau R$ spectra in frontal sunlit area of the trees, by converting $\tau R$ spectra on the same benchmark of solar altitude $\alpha=45^{\circ}$. Main findings are as follows:

- Mean leaf reflectance spectra of various tree species have a minor difference between each other, with spectral reflectance deviations of $\pm 4 \%$, contrasting to substantial differences in spatial distribution of the $\tau R$ across the tree crowns.

- Impact factors of tree crown transflectance (sparse foliage with gaps in crown foliage, concave and convex shapes in crown foliage, solar time): Visibly nonuniform foliage distribution in the measuring patches, such as sparse foliage 
with gaps and concave shapes degrades $\tau R$ levels to different extents. Impact of sparse foliage with gaps and concave shapes on $\tau R$ is complicated and heterogeneous. $\tau R$ in the frontal sunlit area of trees for a specific species is linearly correlated with solar altitude on sunny days, allowing this to be used as a benchmark for comparing differences in intraspecific and interspecific performance.

- Spatial distribution rules: The primary tree crown $\tau R$ in a horizontal loop around tree crowns appears in the frontal sunlit area (SAz direction), followed by those in $\mathrm{SAz}+90^{\circ}$ and $\mathrm{SAz}+270^{\circ}$ clockwise directions. The $\tau R$ on the tree shade side $\left(\mathrm{SAz}+180^{\circ}\right.$ clockwise) has the lowest levels). $\tau R$ distributions in two typically vertical loops perpendicular to each other confirm that the strongest tree crown transflection was found primarily towards sky on the sunlit side of trees rather than towards zenith. The direction of the maximum transflection in the frontal sunlit area varies with solar time and depends on the polar angle consisting of solar azimuth and solar altitude. The $\tau R$ beneath trees has the minimum level.

- Interspecific difference comparison of infrared radiative performance levels indicates that tree species such as Platanus $\mathrm{x}$ acerifolia and Aesculus hippocastanum with large-sized leaves, lead to maximum radiative performance levels, followed by the tree species with moderate-sized leaves (e.g. Acer platanoides, Acer campestre, Quercus robur, Tilia platyphyllos). Sequoiadendron giganteum has the minimum radiative performance level, 
mainly due to its small needle leaves. It reveals that interspecific difference of the infrared radiative performance levels strongly depends on leaf size if visually dense foliage (no obvious gaps in foliage and no concave shapes) is observed on the tree crown contours.

The findings provide insights on understanding radiative interactions between urban trees and the surrounding built environments.

\section{Acknowledgment}

This work is funded by the UK EPSRC/NERC project titled 'InfruTreeCity: Understanding Infrared radiative performance of urban trees for better future city' (Grant number: EP/P023819/1). The authors wish to thank Dr. Christos H. Halios at the University of Reading for demonstrating usages of the Arborcheck instruments in measuring chlorophyll fluorescence and tree physiological stress, the Evolution Spectrometers (model SM2500) as well as some other technical assistance. It is also grateful for the advisory panel members who have attended our meetings to provide valuable advices. Gratitude is also given to Mr. Rupert Taylor at the University of Reading, who helped to identify names of tree species in tests. 


\section{Appendix A. Supplementary materials}

857 Supplementary data associated with this article is openly available in the University of

858 Reading Research Data Archive, in the online version, at:

859 http://dx.doi.org/10.17864/1947.231. Metadata will be available by request.

860

861

Declaration of interest: none.

862

863

References

[1] R. Garcia-Herrera, J. Díaz, R.M. Trigo, J. Luterbacher, E.M. Fischer, A review (2010) 267-306. https://doi.org/10.1080/10643380802238137.

[2] IPCC, Climate Change 2014: Synthesis Report. Contribution of Working Groups

[3] A. Gasparrini, B. Armstrong, The impact of heat waves on mortality, Epidemiology. (2011). https://doi.org/10.1097/EDE.0b013e3181fdcd99.

[4] Y. Guo, A. Gasparrini, B.G. Armstrong, et al., Heat wave and mortality: A multicountry, multicommunity study, Environ. Health Perspect. (2017).

875 [5] E.M. Fischer, R. Knutti, Anthropogenic contribution to global occurrence of heavy-precipitation and high-temperature extremes, Nat. Clim. Chang. 5 (2015) 560-564. https://doi.org/10.1038/nclimate2617.

6] L. Zhao, M. Oppenheimer, Q. Zhu, J.W. Baldwin, K.L. Ebi, E. Bou-Zeid, K. 
Guan, X. Liu, Interactions between urban heat islands and heat waves, Environ. Res. Lett. 13 (2018) 034003. https://doi.org/10.1088/1748-9326/aa9f73.

[7] C.C. Konijnendijk, K. Nilsson, T.B. Randrup, J. Schipperijn, Urban forests and trees: A reference book, 2005. https://doi.org/10.1007/3-540-27684-X.

[8] R. Upreti, Z.H. Wang, J. Yang, Radiative shading effect of urban trees on cooling the regional built environment, Urban For. Urban Green. 26 (2017) 18-24. https://doi.org/10.1016/j.ufug.2017.05.008.

[9] Z. Zou, Y. Yang, G.Y. Qiu, Quantifying the evapotranspiration rate and its cooling effects of urban hedges based on three-temperature model and infrared remote sensing, $\quad$ Remote Sens. $11 \quad$ (2019) 1-18. https://doi.org/10.3390/rs11020202.

[10] M. Taleghani, Outdoor thermal comfort by different heat mitigation strategiesA review, Renew. Sustain. Energy Rev. 81 (2018) 2011-2018. https://doi.org/10.1016/j.rser.2017.06.010.

[11] L. Kong, K.K.L. Lau, C. Yuan, Y. Chen, Y. Xu, C. Ren, E. Ng, Regulation of outdoor thermal comfort by trees in Hong Kong, Sustain. Cities Soc. 31 (2017) 12-25. https://doi.org/10.1016/j.scs.2017.01.018.

[12] Z.H. Wang, X. Zhao, J. Yang, J. Song, Cooling and energy saving potentials of shade trees and urban lawns in a desert city, Appl. Energy. 16 (2016) 437-444. https://doi.org/10.1016/j.apenergy.2015.10.047.

[13] S. Gillner, J. Vogt, A. Tharang, S. Dettmann, A. Roloff, Role of street trees in mitigating effects of heat and drought at highly sealed urban sites, Landsc. Urban 
Plan. 143 (2015) 33-42. https://doi.org/10.1016/j.landurbplan.2015.06.005.

[14] H. Lee, H. Mayer, L. Chen, Contribution of trees and grasslands to the mitigation of human heat stress in a residential district of Freiburg, Southwest Germany, Landsc. Urban Plan. $148 \quad$ (2016) 37-50. https://doi.org/10.1016/j.landurbplan.2015.12.004.

[15] A.S. Yang, Y.H. Juan, C.Y. Wen, C.J. Chang, Numerical simulation of cooling effect of vegetation enhancement in a subtropical urban park, Appl. Energy. 192 (2017) 178-200. https://doi.org/10.1016/j.apenergy.2017.01.079.

[16] D.E. Bowler, L. Buyung-Ali, T.M. Knight, A.S. Pullin, Urban greening to cool towns and cities: A systematic review of the empirical evidence, Landsc. Urban Plan. 97 (2010) 147-155. https://doi.org/10.1016/j.landurbplan.2010.05.006.

[17] W. Zhou, J. Wang, M.L. Cadenasso, Effects of the spatial configuration of trees on urban heat mitigation: A comparative study, Remote Sens. Environ. 195 (2017) 1-12. https://doi.org/10.1016/j.rse.2017.03.043.

[18] S. Sodoudi, H. Zhang, X. Chi, F. Müller, H. Li, The influence of spatial configuration of green areas on microclimate and thermal comfort, Urban For. Urban Green. 34 (2018) 85-96. https://doi.org/10.1016/j.ufug.2018.06.002.

[19] Z. Tan, K.K.L. Lau, E. Ng, Urban tree design approaches for mitigating daytime urban heat island effects in a high-density urban environment, Energy Build. 114 (2016) 265-274. https://doi.org/10.1016/j.enbuild.2015.06.031.

[20] T. Zölch, M.A. Rahman, E. Pfleiderer, G. Wagner, S. Pauleit, Designing public squares with green infrastructure to optimize human thermal comfort, Build. 

Environ. 149 (2019) 640-654. https://doi.org/10.1016/j.buildenv.2018.12.051.

[21] E. Jamei, P. Rajagopalan, M. Seyedmahmoudian, Y. Jamei, Review on the impact of urban geometry and pedestrian level greening on outdoor thermal comfort, Renew. Sustain. Energy Rev. $54 \quad$ (2016) 1002-1017. https://doi.org/10.1016/j.rser.2015.10.104.

[22] Y. Wang, U. Berardi, H. Akbari, Comparing the effects of urban heat island mitigation strategies for Toronto, Canada, Energy Build. 114 (2016) 2-19. https://doi.org/10.1016/j.enbuild.2015.06.046.

[23] Y. Liu, D.J. Harris, Effects of shelterbelt trees on reducing heating-energy consumption of office buildings in Scotland, Appl. Energy. 85 (2008) 115-127. https://doi.org/10.1016/j.apenergy.2007.06.008.

[24] J.L. Moss, K.J. Doick, S. Smith, M. Shahrestani, Influence of evaporative cooling by urban forests on cooling demand in cities, Urban For. Urban Green. 37 (2019) 65-73. https://doi.org/10.1016/j.ufug.2018.07.023.

[25] C.M. Hsieh, J.J. Li, L. Zhang, B. Schwegler, Effects of tree shading and transpiration on building cooling energy use, Energy Build. 159 (2018) 382-397. https://doi.org/10.1016/j.enbuild.2017.10.045.

[26] N. Bréda, V. Badeau, Forest tree responses to extreme drought and some biotic events: Towards a selection according to hazard tolerance?, Comptes Rendus Geosci. 340 (2008) 651-662. https://doi.org/10.1016/j.crte.2008.08.003.

[27] C. Calfapietra, J. Peñuelas, Ü. Niinemets, Urban plant physiology: Adaptationmitigation strategies under permanent stress, Trends Plant Sci. 20 (2015) 72-75. 
https://doi.org/10.1016/j.tplants.2014.11.001.

[28] R. Teskey, T. Wertin, I. Bauweraerts, M. Ameye, M.A. McGuire, K. Steppe, Responses of tree species to heat waves and extreme heat events, Plant Cell Environ. 38 (2015) 1699-1712. https://doi.org/10.1111/pce.12417.

[29] I. Bauweraerts, M. Ameye, T.M. Wertin, M.A. McGuire, R.O. Teskey, K. Steppe, Water availability is the decisive factor for the growth of two tree species in the occurrence of consecutive heat waves, Agric. For. Meteorol. 189-190 (2014) 1929. https://doi.org/10.1016/j.agrformet.2014.01.001.

[30] S. Leuzinger, R. Vogt, C. Körner, Tree surface temperature in an urban environment, Agric. For. Meteorol. $150 \quad$ (2010) 56-62. https://doi.org/10.1016/j.agrformet.2009.08.006.

[31] S. Zheng, J.M. Guldmann, Z. Liu, L. Zhao, Influence of trees on the outdoor thermal environment in subtropical areas: An experimental study in Guangzhou, China, Sustain. Cities Soc. $42 \quad$ (2018) 482-497. https://doi.org/10.1016/j.scs.2018.07.025.

[32] M.A. Irmak, S. Yilmaz, E. Mutlu, H. Yilmaz, Assessment of the effects of different tree species on urban microclimate, Environ. Sci. Pollut. Res. 25 (2018) 15802-15822. https://doi.org/10.1007/s11356-018-1697-8.

[33] C.Y. Park, D.K. Lee, E.S. Krayenhoff, H.K. Heo, S. Ahn, T. Asawa, A. Murakami, H.G. Kim, A multilayer mean radiant temperature model for pedestrians in a street canyon with trees, Build. Environ. 141 (2018) 298-309. https://doi.org/10.1016/j.buildenv.2018.05.058. 
967

968

969

970

971

972

973

974

975

976

977

978

979

980

981

982

983

984

985

986

987

988

[34] C.Y. Park, D.K. Lee, E.S. Krayenhoff, H.K. Heo, J.H. Hyun, K. Oh, T.Y. Park, Variations in pedestrian mean radiant temperature based on the spacing and size of street trees, Sustain. Cities Soc. 48 (2019) 1-9. https://doi.org/10.1016/j.scs.2019.101521.

[35] T. Zölch, J. Maderspacher, C. Wamsler, S. Pauleit, Using green infrastructure for urban climate-proofing: An evaluation of heat mitigation measures at the microscale, Urban For. Urban Green. 20 (2016) 305-316. https://doi.org/10.1016/j.ufug.2016.09.011.

[36] T.E. Morakinyo, K.K.L. Lau, C. Ren, E. Ng, Performance of Hong Kong's common trees species for outdoor temperature regulation, thermal comfort and energy saving, Build. Environ. $137 \quad$ (2018) 157-170. https://doi.org/10.1016/j.buildenv.2018.04.012.

[37] D. Armson, M.A. Rahman, A.R. Ennos, A comparison of the shading effectiveness of five different street tree species in Manchester, UK, Arboric. Urban For. 39 (2013) 157-164.

[38] M.A. Rahman, D. Armson, A.R. Ennos, A comparison of the growth and cooling effectiveness of five commonly planted urban tree species, Urban Ecosyst. 18 (2015) 371-389. https://doi.org/10.1007/s11252-014-0407-7.

[39] L. Zhang, Q. Zhan, Y. Lan, Effects of the tree distribution and species on outdoor environment conditions in a hot summer and cold winter zone: A case study in Wuhan residential quarters, Build. Environ. $130 \quad$ (2018) 27-39. https://doi.org/10.1016/j.buildenv.2017.12.014. 
989

990

991

992

993

994

995

996

997

998

999

1000

1001

1002

1003

1004

1005

1006

1007

1008

1009

1010

[40] R. Sanusi, D. Johnstone, P. May, S.J. Livesley, Microclimate benefits that different street tree species provide to sidewalk pedestrians relate to differences in Plant Area Index, Landsc. Urban Plan. 157 (2017) 502-511. https://doi.org/10.1016/j.landurbplan.2016.08.010.

[41] X. Chen, P. Zhao, Y. Hu, et al., Canopy transpiration and its cooling effect of three urban tree species in a subtropical city- Guangzhou, China, Urban For. Urban Green. 43 (2019) 126368. https://doi.org/10.1016/j.ufug.2019.126368.

[42] M. Jiao, W. Zhou, Z. Zheng, et al., Patch size of trees affects its cooling effectiveness: A perspective from shading and transpiration processes, Agric. For. Meteorol. 247 (2017) 293-299. https://doi.org/10.1016/j.agrformet.2017.08.013.

[43] E. Litvak, H.R. McCarthy, D.E. Pataki, A method for estimating transpiration of irrigated urban trees in California, Landsc. Urban Plan. 158 (2017) 48-61. https://doi.org/10.1016/j.landurbplan.2016.09.021.

[44] M.A. Rahman, A. Moser, A. Gold, T. Rötzer, S. Pauleit, Vertical air temperature gradients under the shade of two contrasting urban tree species during different types of summer days, Sci. Total Environ. 633 (2018) 100-111. https://doi.org/10.1016/j.scitotenv.2018.03.168.

[45] J. Konarska, J. Uddling, B. Holmer, M. Lutz, F. Lindberg, H. Pleijel, S. Thorsson, Transpiration of urban trees and its cooling effect in a high latitude city, Int. J. Biometeorol. 60 (2016) 159-172. https://doi.org/10.1007/s00484-015-1014-x.

[46] C. Wang, Z.H. Wang, C. Wang, S.W. Myint, Environmental cooling provided by urban trees under extreme heat and cold waves in U.S. cities, Remote Sens. 

Environ. 227 (2019) 28-43. https://doi.org/10.1016/j.rse.2019.03.024.

[47] M.A. Rahman, A. Moser, T. Rötzer, S. Pauleit, Comparing the transpirational and shading effects of two contrasting urban tree species, Urban Ecosyst. 22 (2019) 683-697. https://doi.org/10.1007/s11252-019-00853-x.

[48] W.T.L. Chow, A.J. Brazel, Assessing xeriscaping as a sustainable heat island mitigation approach for a desert city, Build. Environ. 47 (2012) 170-181. https://doi.org/10.1016/j.buildenv.2011.07.027.

[49] A. Middel, N. Chhetri, R. Quay, Urban forestry and cool roofs: Assessment of heat mitigation strategies in Phoenix residential neighborhoods, Urban For. Urban Green. 14 (2015) 178-186. https://doi.org/10.1016/j.ufug.2014.09.010.

[50] C.Y. Park, D.K. Lee, E.S. Krayenhoff, et al., Variations in pedestrian mean radiant temperature based on the spacing and size of street trees, Sustain. Cities Soc. (2019). https://doi.org/10.1016/j.scs.2019.101521.

[51] L.V. de Abreu-Harbich, L.C. Labaki, A. Matzarakis, Effect of tree planting design and tree species on human thermal comfort in the tropics, Landsc. Urban Plan. 138 (2015) 99-109. https://doi.org/10.1016/j.landurbplan.2015.02.008.

[52] Z. Tan, K.K.L. Lau, E. Ng, Planning strategies for roadside tree planting and outdoor comfort enhancement in subtropical high-density urban areas, Build. Environ. 120 (2017) 93-109. https://doi.org/10.1016/j.buildenv.2017.05.017.

[53] Z. Wu, L. Chen, Optimizing the spatial arrangement of trees in residential neighborhoods for better cooling effects: Integrating modeling with in-situ measurements, Landsc. Urban Plan. $167 \quad$ (2017) 463-472. 
1034

1035

1036

1037

1038

1039

1040

1041

1042

1043

1044

1045

1046

1047

1048

1049

1050

1051

1052

1053

1054

[54] Z. Wu, P. Dou, L. Chen, Comparative and combinative cooling effects of different spatial arrangements of buildings and trees on microclimate, Sustain. Cities Soc. (2019). https://doi.org/10.1016/j.scs.2019.101711.

[55] Q. Zhao, D.J. Sailor, E.A. Wentz, Impact of tree locations and arrangements on outdoor microclimates and human thermal comfort in an urban residential environment, Urban For. Urban Green. $32 \quad$ (2018) 81-91. https://doi.org/10.1016/j.ufug.2018.03.022.

[56] M. Aminipouri, D. Rayner, F. Lindberg, et al., Urban tree planting to maintain outdoor thermal comfort under climate change: The case of Vancouver's local climate zones, Build. Environ. $158 \quad$ (2019) 226-236. https://doi.org/10.1016/j.buildenv.2019.05.022.

[57] Z.H. Wang, Monte Carlo simulations of radiative heat exchange in a street canyon with trees, Sol. Energy. $110 \quad$ (2014) 704-713. https://doi.org/10.1016/j.solener.2014.10.012.

[58] T.E. Morakinyo, Y.F. Lam, Simulation study on the impact of tree-configuration, planting pattern and wind condition on street-canyon's micro-climate and thermal comfort, Build. Environ. $103 \quad$ (2016) 262-275. https://doi.org/10.1016/j.buildenv.2016.04.025.

[59] T. Eckmann, A. Morach, M. Hamilton, et al., A. McNamee, A. Haripriyan, D. Castillo, S. Grandy, A. Kessi, Measuring and modeling microclimate impacts of Sequoiadendron giganteum, Sustain. Cities Soc. 38 (2018) 509-525. 
https://doi.org/10.1016/j.scs.2017.12.028.

[60] S.H. Lee, S.U. Park, A vegetated urban canopy model for meteorological and environmental modelling, Boundary-Layer Meteorol. 126 (2008) 73-102. https://doi.org/10.1007/s10546-007-9221-6.

[61] H. Simon, J. Lindén, D. Hoffmann, P. Braun, M. Bruse, J. Esper, Modeling transpiration and leaf temperature of urban trees - A case study evaluating the microclimate model ENVI-met against measurement data, Landsc. Urban Plan. 174 (2018) 33-40. https://doi.org/10.1016/j.landurbplan.2018.03.003.

[62] J. Deng, B.J. Pickles, A. Kavakopoulos, T. Blanusa, C.H. Halios, S.T. Smith, L. Shao, Concept and methodology of characterising infrared radiative performance of urban trees using tree crown spectroscopy, Build. Environ. 157 (2019) 380-390. https://doi.org/10.1016/j.buildenv.2019.04.056.

[63] British Trees: native and non-native trees. https://www.woodlandtrust.org.uk/visiting-woods/trees-woods-andwildlife/british-trees/ (accessed June 21, 2019).

[64] C.F. Dietrich, Uncertainty, calibration and probability: The statistics of scientific and industrial measurement, 2nd ed., New York, 1991. https://doi.org/10.1201/9780203734759.

[65] R Core Team, R: A language and environment for statistical computing, (2019). https://www.r-project.org/.

[66] W.H. Oksanen J, Blanchet FG, Friendly M, et al., vegan: Community Ecology Package. $\mathrm{R}$ package version 2.5-6, (2019). https://cran.r- 
project.org/package=vegan.

1078

1079

1080

1081

1082

1083

1084

1085

1086

1087

1088

1089

1090

1091

1092

1093

1094

1095

1096

[67] M.F. Kassambara A, factoextra: Extract and Visualize the Results of Multivariate Data Analyses, (2017). https://cran.r-project.org/package=factoextra.

[68] S. Lê, J. Josse, F. Husson, FactoMineR: An R package for multivariate analysis, J. Stat. Softw. 25 (2008) 1-18. https://doi.org/10.18637/jss.v025.i01.

[69] P. Legendre, L. Legendre, Numerical Ecology, 3rd Editio, Elsevier, Amsterdam, Netherlands, 2012. $\quad$ https://www.elsevier.com/books/numericalecology/legendre/978-0-444-53868-0.

[70] J. Cavender-Bares, J.E. Meireles, J.J. Couture, et al., Associations of leaf spectra with genetic and phylogenetic variation in oaks: Prospects for remote detection of biodiversity, Remote Sens. 8 (2016). https://doi.org/10.3390/rs8030221.

[71] ImageJ User Guide. https://imagej.nih.gov/ij/docs/guide/index.html (accessed September 20, 2019).

[72] Reading, ENG, United Kingdom - Sunrise, Sunset, and Moon Times. https://www.timeanddate.com/astronomy/uk/reading (accessed June 10, 2019).

[73] Horse chestnut leaf-mining moth. https://www.rhs.org.uk/advice/profile?pid=533 (accessed September 8, 2019).

[74] D.S. Falster, M. Westoby, Leaf size and angle vary widely across species: What consequences for light interception?, New Phytol. 158 (2003) 509-525. https://doi.org/10.1046/j.1469-8137.2003.00765.x. 